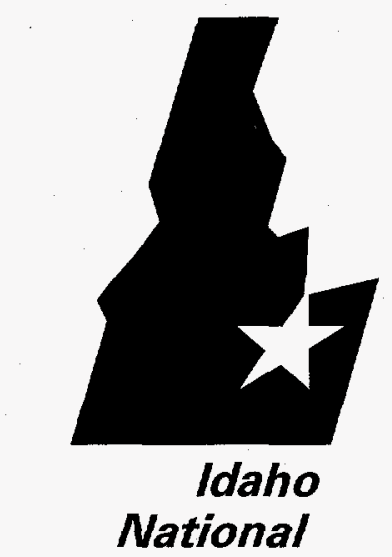

Engineering Laboratory
INEEL/EXT-97-00699

June 1997

\title{
Evaluation of Strain Levels in the IFSF Rack
}

W. D. Richins

G. K. Miller

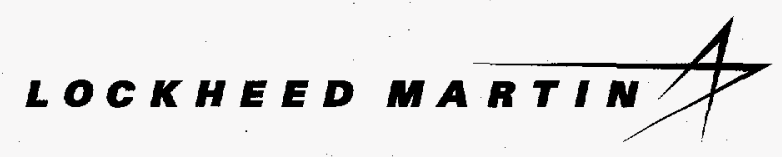




\title{
Evaluation of Strain Levels in the IFSF Rack
}

\author{
W. D. Richins
}

G. K. Miller

June 1997

Idaho National Engineering and Environmental Laboratory Speciality Engineering and Science Department Applied Mechanics

Lockheed Martin Idaho Technologies Company Idaho Falls, Idaho 83415

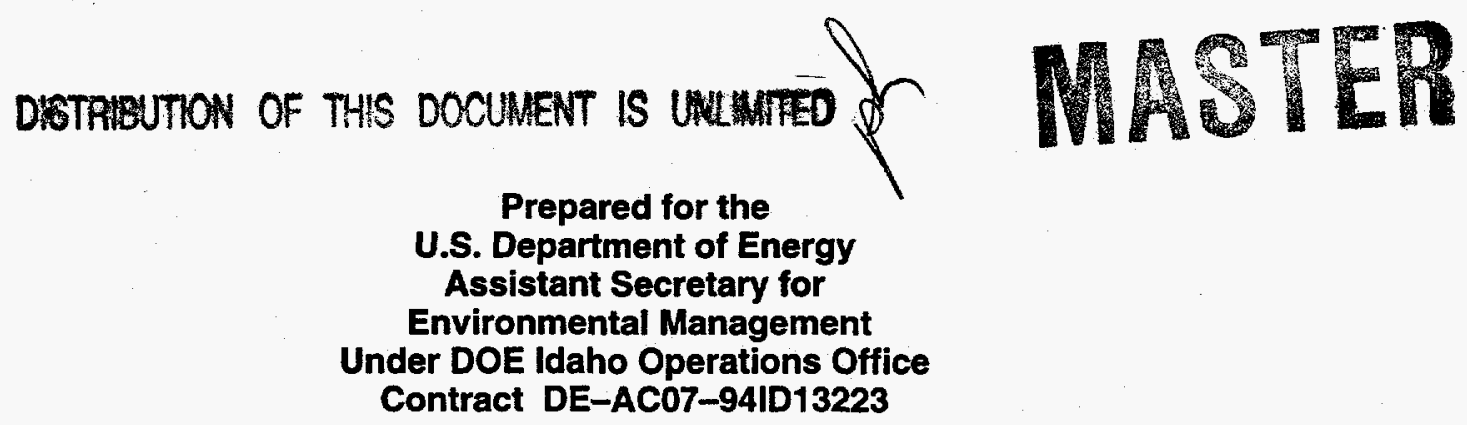




\section{DISCLAIMER}

Portions of this document may be illegible electronic image products. Images are produced from the best available original document. 
Prepared by:

Independent Verification Per NQA-1 by:

Approved by:
WDDLhums June 20,1997

Applied Mechanics

Ix miller

$$
6-20-97
$$

G. K. Miller

Applied Mechanics

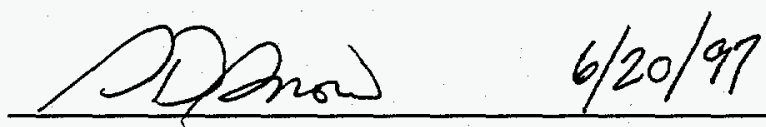

S. D. Snow

Applied Mechanics

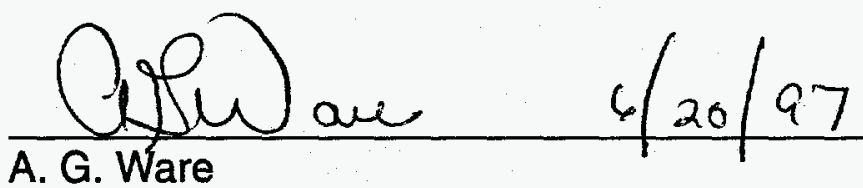

Supervisor, Applied Mechanics 


\begin{abstract}
An evaluation has been performed on strain levels determined for the IFSF fuel storage rack for seismic loading. The storage rack had been previously analyzed by a consulting company, Advanced Engineering Consultants (AEC), who reported significant strain levels in several members of the rack. The purpose for the study conducted herein was to refine the method for calculating strain levels, and then to assess the acceptability of the refined strain values. This was accomplished by making a modification to AEC's model to more realistically represent plastic behavior in all locations where material yields. An analysis was performed where this modified model was subjected to the same seismic loadings as applied in AEC's analysis. It was expected that the more realistic representation of plastic behavior in the modified model would result in reduced maximum calculated strains for the rack.
\end{abstract}

Results of the analysis showed that the more realistic representation of plastic behavior in rack members did reduce the calculated maximum strains from those reported by AEC. These modified strains were evaluated for acceptability according to ductility criteria of the governing standard (i.e. ANSI/AISC N690-1994, as specified by the project Criteria Application Document). This evaluation showed that the strains meet these acceptance criteria. The analysis described herein was performed only to investigate this issue. AEC's analysis stands as the analysis of record for the rack. 


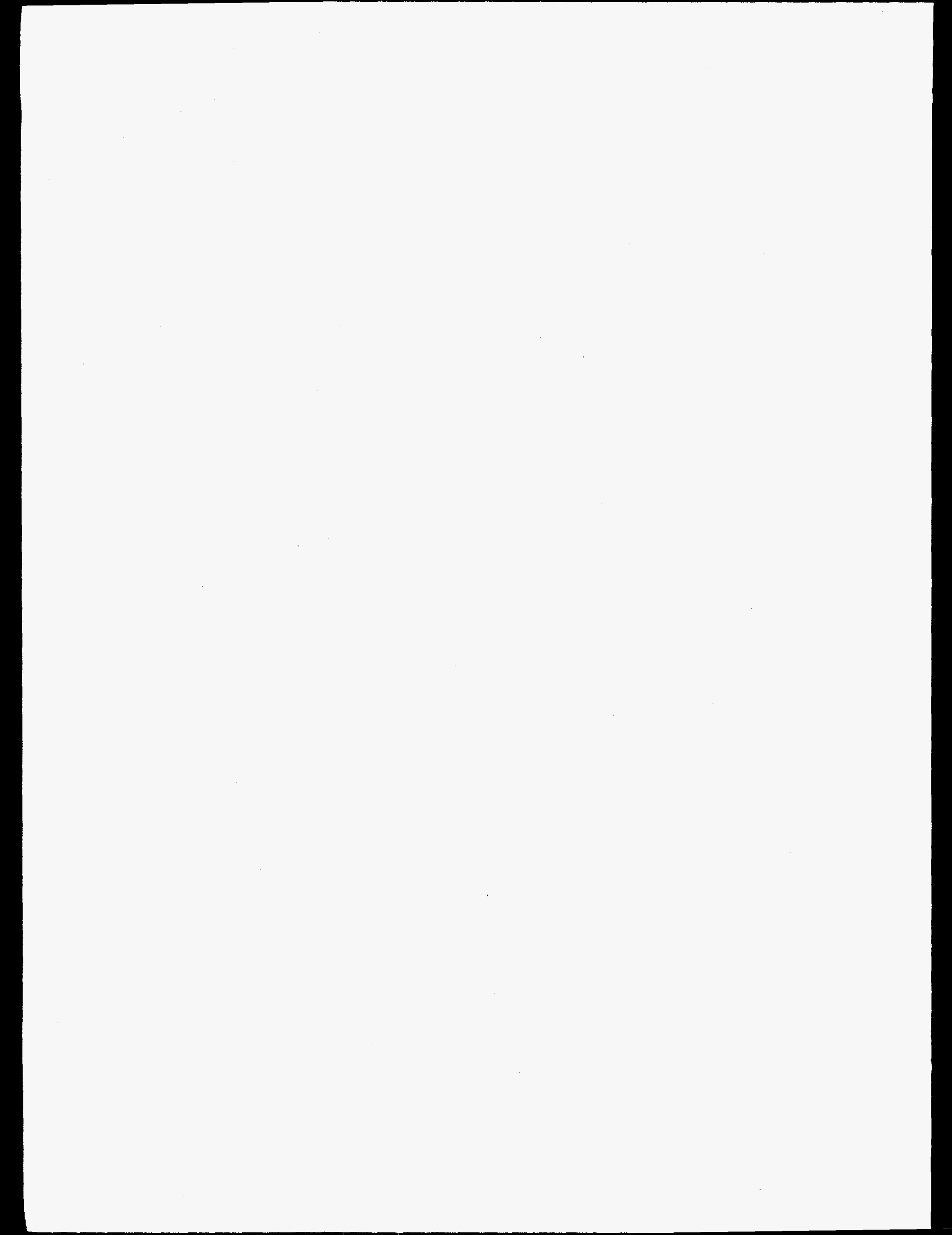




\section{CONTENTS}

1. Introduction $\ldots \ldots \ldots \ldots \ldots \ldots \ldots \ldots \ldots \ldots \ldots \ldots \ldots \ldots \ldots \ldots, 1$

2. Elastic-Plastic Material Properties for A36 Steel .......... 3

3. Finite Element Analyses $\ldots \ldots \ldots \ldots \ldots \ldots \ldots \ldots \ldots \ldots \ldots \ldots \ldots$

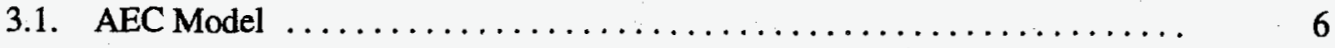

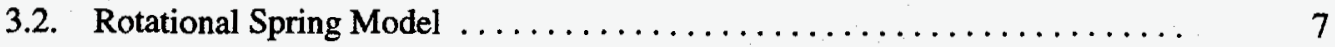

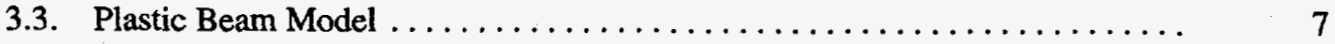

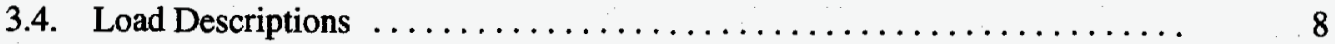

4. Analysis Results $\ldots \ldots \ldots \ldots \ldots \ldots \ldots \ldots \ldots \ldots \ldots \ldots \ldots \ldots \ldots$

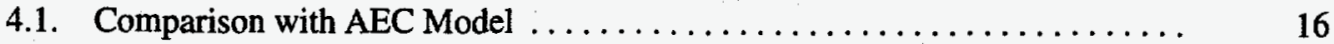

4.2. Strains, Displacements in Plastic Beam Model ................. 19

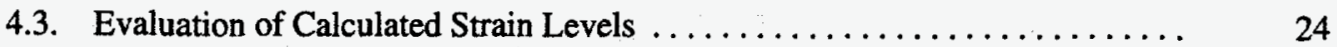

4.4. East-West Loading $\ldots \ldots \ldots \ldots \ldots \ldots \ldots \ldots \ldots \ldots \ldots \ldots \ldots \ldots \ldots \ldots \ldots \ldots, 25$

5. Tubular Beam Behavior - Literature Search ............ 27

6. Conclusions $\ldots \ldots \ldots \ldots \ldots \ldots \ldots \ldots \ldots \ldots \ldots \ldots \ldots \ldots \ldots \ldots \ldots \ldots .29$

7. References $\ldots \ldots \ldots \ldots \ldots \ldots \ldots \ldots \ldots \ldots \ldots \ldots \ldots \ldots \ldots \ldots \ldots ., 30$

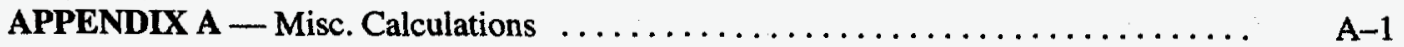

APPENDIX B - Beam Section Data $\ldots \ldots \ldots \ldots \ldots \ldots \ldots \ldots \ldots \ldots \ldots \ldots \ldots \ldots \ldots$, B-1

APPENDIX C - Computer Verification and Sample Data $\ldots \ldots \ldots \ldots \ldots \ldots, \mathbf{C}-1$ 


\section{FIGURES}

Figure 1 . Typical Stress - Strain Curve for A36 Steel $\ldots \ldots \ldots \ldots \ldots$.

Figure 2. A36 True Stress - True Strain Curves ............... 4

Figure 3. AEC Model of the IFSF Rack ................. 9

Figure 4 . Close-up View of NW Corner of IFSF Rack Model . . . . . . . 10

Figure 5 . Details of AEC and Rotational Spring Models ........... 12

Figure 6. Details of Non-Linear Springs .................. 13

Figure 7 . Details of Fuel Canister Modeling ................. 14

Figure 8 . Details of Plastic Beam Model at NW Corner ............ 15

Figure 9. Comparison of Deformed Shapes, ............... 17

Figure 10. Maximum Strains Calculated in the Plastic Beam Model .... 21

Figure 11. Plastic Beam Model Deformed Shape .............. 23

\section{TABLES}

Table 1. Stress - Strain Data for A36 Steel ............... 5

Table 2. Material Properties for A36 Steel Used in ABAQUS Analysis .. 5

Table 3. Analysis Steps for ABAQUS Analyses .............. 8

Table 4 . Comparison of Displacements for $\mathrm{N}-\mathrm{S}$ Direction .......... 16

Table 5. Maximum Total Strains ...................... 19 


\section{Evaluation of Strain Levels in the IFSF Rack}

\section{INTRODUCTION}

The IFSF (Irradiated Fuel Storage Facility) fuel storage rack (Ref. 1) is a carbon steel space frame structure located within the storage room of the IFSF at the Idaho Chemical Processing Plant. The rack is approximately $36 \mathrm{ft}$ (N/S direction) $\times 68 \mathrm{ft} \times 10.5 \mathrm{ft}$ high and accepts up to 636 removable fuel canisters with maximum weight of $1836 \mathrm{lbs}$ each (Ref. 2). The canisters are approximately $11 \mathrm{ft} x 18 \mathrm{in}$. dia tubes with a sealed base and a removable lid at the top. The exterior columns of the rack are $2.5 \times 5-$ in. structural tubing and are not anchored to the floor. The interior columns are $5 \times 5-$ in. tubing and are welded to steel inserts which are bolted to the basemat. The columns are welded to three tiers of horizontal members consisting of angles, pipes, and structural tubing. The fuel canisters bear on the stems of inverted structural tee members placed on the concrete basemat such that, during normal operation, the rack structure does not support the weight of the fuel canisters.

Advanced Engineering Consultants (AEC) performed a seismic analysis (Ref. 2) of the IFSF Storage Rack. From their analysis, AEC reported strain levels in several of the exterior columns ranging as high as 9\%. The Defense Nuclear Facilities Safety Board (DNFSB) Staff questioned the acceptability of the strain levels reported. In AEC's analysis of the rack structure, exterior columns and other beam-like members in the structure that exhibit plastic behavior were represented with equivalent beams that consist of an elastic beam with nonlinear rotational springs at its end(s). All of the plastic behavior in these elements was concentrated in these rotational springs at the ends of the element. This modeling approach should give a reasonable representation of rack behavior, but can be expected to overestimate strain levels at the ends of the equivalent beams. The highest strains calculated in AEC's analysis were strains due to bending at the ends of exterior column elements. The column elements where these strains occurred were among the elements modeled with equivalent beams.

The following steps were taken to refine the strain levels calculated in AEC's analysis.

(1) AEC's model of the rack (an ANSYS model, Ref. 3) was converted to an ABAQUS (Ref. 4) model (referred to here as the Plastic Beam Model) so that an analysis using plastic beam elements could be performed. In this model, all of AEC's equivalent beams were replaced with ABAQUS plastic beam elements. The plastic beam elements were modeled with elastic-plastic material properties representative of A36 steel. The North-South (N/S) model was analyzed in this manner, since it was reported to give the maximum strain value in AEC's analysis. (The N/S ANSYS model used by AEC is referred to here as the AEC Model.) Section 4.4 provides further discussion of E/W loading. The same loads were applied to the Plastic Beam Model as were used in AEC's analysis. This analysis produced more realistic maximum strains in these members than were calculated in AEC's analysis.

(2) To verify the conversion of the AEC Model to ABAQUS, an ABAQUS model was also solved without modifying any of AEC's equivalent beams (referred to here as the Rotational Spring Model). This analysis solved the same problem as solved by AEC, but used ABAQUS instead of ANSYS. The verification was made by comparing results from this solution to results obtained by AEC. Results compared were rack displacements at various key locations within the rack structure and the deformed shapes of the two models.

(3) Results obtained from the Plastic Beam Model analysis were used to determine whether the calculated strains meet an acceptable strain limit. The rack members have closed cross-sections and are of medium size. Based on ANSI/AISC N690-1994 criteria (Ref. 
5), a strain of $2.5 \%$ is considered to be an acceptable strain limit for these members. Since the calculated strains lie within this limit, the conclusion was reached that the rack structure is acceptable. Though experimental data for tubular structures representative of the IFSF rack is scant, a literature review on the subject supports the conclusion that the strain levels are acceptable.

The analysis performed in this investigation was intended only to confirm that the calculated strain levels are acceptable. It was not intended to supplant AEC's analysis, which will still stand as the analysis of record for the rack. 


\section{ELASTIC-PLASTIC MATERIAL PROPERTIES FOR A36 STEEL}

The calculated strain levels for the plastic beams are expected to be sensitive to the strain hardening used for the material. It is therefore important that the elastic-plastic properties be representative for A36 steel. The properties used in this analysis were obtained from the Structural Alloys Handbook (Ref. 6). A stress-strain curve for A36 steel from that handbook is presented in Fig. 1. The material behaves elastically to point $A$ on the curve. The following elastic properties were used, which correspond to those used in AEC's original analysis:

$$
\begin{aligned}
& \mathrm{E}=\text { Elastic Modulus }=29.0 \times 10^{6} \mathrm{psi} \\
& v=\text { Poisson's Ratio }=0.3 \\
& \sigma_{\mathrm{y}}=\text { Yield Stress }=36000 \mathrm{psi}
\end{aligned}
$$

The strain levels shown in the figure are actually measures of elongation. Up to the strain level of 0.12 (point $B$ ), deformation along the length of the test specimen is uniform (no necking) and the strain level represents engineering (or nominal) strain. The test specimen begins to neck down at point $B$, and deformation is no longer uniform. The stress values on the curve are engineering (or nominal) stresses. In the plastic analysis performed, the ABAQUS program utilizes true stresses and strains. Therefore, the nominal stress and strain values for several points between $A$ and $B$ on the attached curve were converted to true stress and true strain using the following equations (Ref. 4).

True stress $\left(\sigma_{\text {true }}\right)$ :

$$
\sigma_{\text {true }}=\sigma_{\text {nom }}\left(1+\epsilon_{\text {nom }}\right)
$$

True plastic strain $\left(\varepsilon_{\mathrm{tr}}{ }^{\mathrm{pl}}\right)$ :

$$
\epsilon_{t r}^{p l}=\ln \left(1+\epsilon_{\text {nom }}\right)-\frac{\sigma_{\text {true }}}{E}
$$

It is not expected that strain levels will exceed 0.12 in this analysis. The stress-strain data are shown in Fig. 2 (solid curve) and listed in Table 1 .

The relatively sharp discontinuity at the yield point in the stress -strain curve creates convergence difficulties during non-linear finite element analyses. The true stress-strain curve was smoothed as shown by the dashed curve in Fig. 2 to relieve these convergence problems. The properties used as input for ABAQUS are listed in Table 2 . 


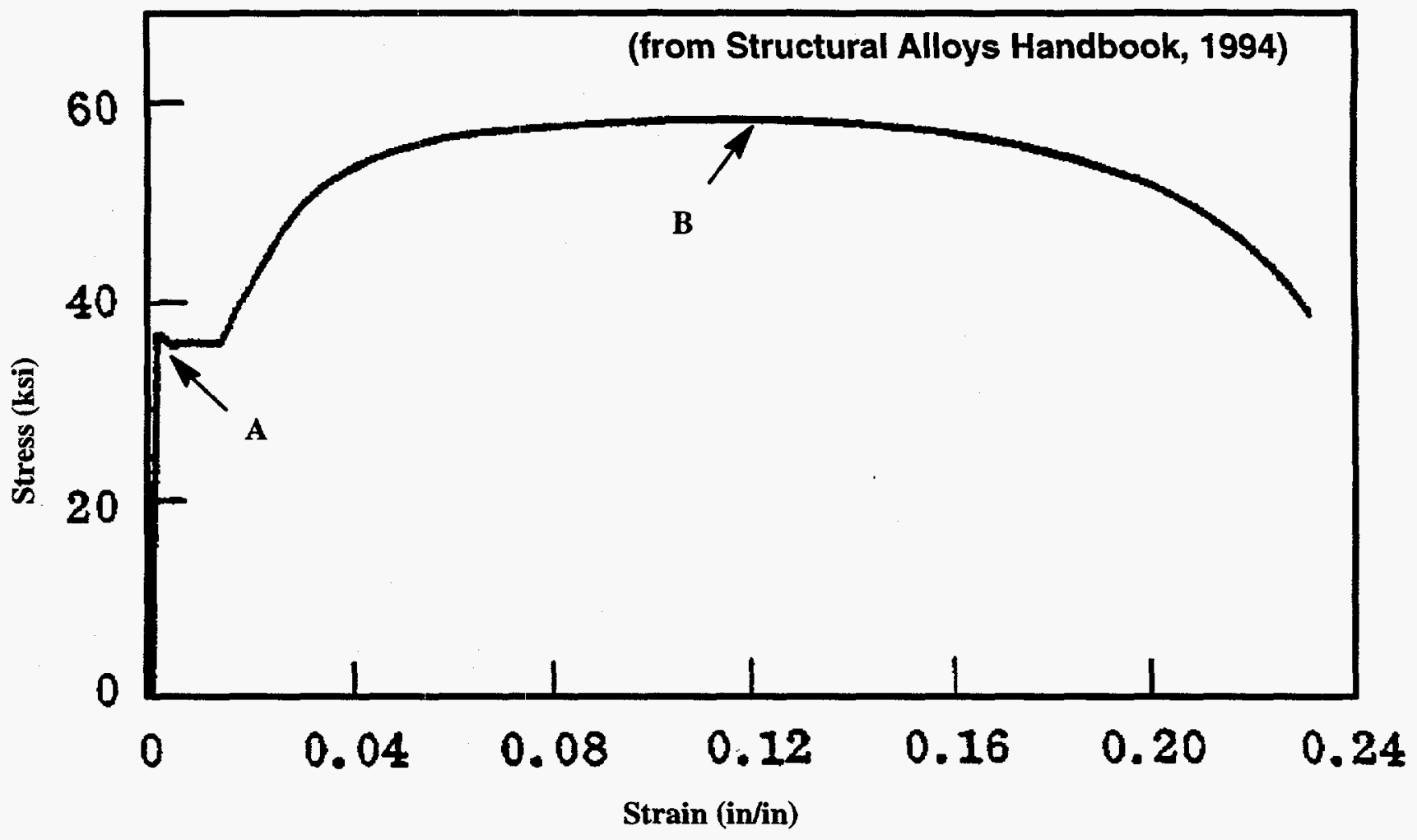

Figure 1. Typical Stress - Strain Curve for A36 Steel

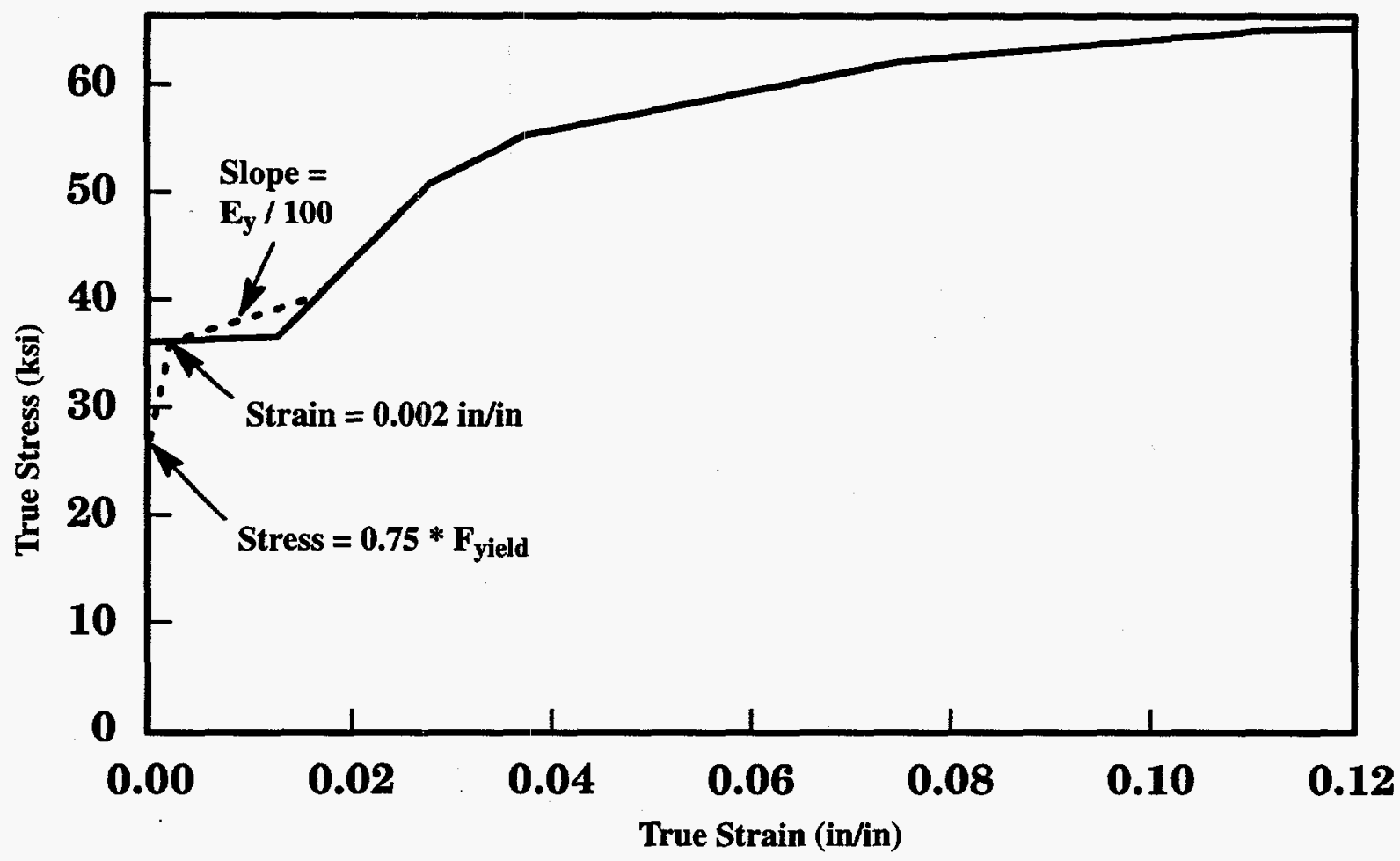

Figure 2. A36 True Stress - True Strain Curves, Solid Curve is from Table 1, Dashed Curve is Smoothed Data used in ABAQUS Analyses, Table 2. 
Table 1 . Stress - Strain Data for A36 Steel Based on Fig. 1

\begin{tabular}{|c|c|c|c|}
\hline$\varepsilon_{\text {nom }}$ & $\sigma_{\text {nom, psi }}$ & $\sigma_{\text {true, psi }}$ & $\varepsilon_{\text {tr }}$ pl \\
\hline 0.00124 & 36000 & 36044 & 0. \\
\hline 0.014 & 36000 & 36504 & 0.0126 \\
\hline 0.03 & 49230 & 50707 & 0.0278 \\
\hline 0.04 & 53070 & 55193 & 0.0373 \\
\hline 0.08 & 57430 & 62024 & 0.0748 \\
\hline 0.12 & 58000 & 64960 & 0.111 \\
\hline
\end{tabular}

It is noted that the yield stress and ultimate tensile stress of 36000 and $58000 \mathrm{psi}$ (nominal), respectively, are consistent with minimum values of the ASTM Specification A 36/A 36M (Ref. 7).

Table 2 . Material Properties for A36 Steel Used in ABAQUS Analysis

\begin{tabular}{|c|c|}
\hline$\sigma_{\text {true, psi }}$ & $\varepsilon_{\text {tr }}$ pl \\
\hline 27000 & 0. \\
\hline 36044 & 0.002 \\
\hline 40295 & 0.01666 \\
\hline 50707 & 0.0278 \\
\hline 55193 & 0.0373 \\
\hline 62024 & 0.0748 \\
\hline 64960 & 0.111 \\
\hline
\end{tabular}




\section{FINITE ELEMENT ANALYSES}

The IFSF rack was initially analyzed by AEC (Ref. 2) using the ANSYS program (Ref. 3). Only the N/S AEC model is addressed here. Results expected for the East-West model are discussed in Section 4.4. A half model was used by AEC since the rack and all N/S loads are approximately symmetric about a N/S plane through the rack. Symmetry boundary conditions were applied to nodes on this plane. The AEC N/S non-linear spring model is referred to here as the AEC Model.

The AEC Model was translated directly to an ABAQUS Standard input file (Ref. 4) by AEC. This file, however, included only node geometry and element definitions. The input file was then read into I-DEAS solid modeling software (Ref. 8) which was used as a preprocessor to apply loads and boundary conditions, add elements as necessary, check models, etc. Two models were then developed for analysis using ABAQUS; 1) the Rotational Spring Model which replicates as closely as possible the AEC Model but in ABAQUS format, and 2) the Plastic Beam Model which replaces the non-linear rotational springs with beams having non-linear material behavior. All finite element models were then converted to ABAQUS Standard format and processed on DEC ALPHA hardware. The basic beam geometry for all three models is shown in Figs. 3 and 4 . Appendix B contains the beam cross section data as evaluated by I-DEAS (used only for the elastic beams in the Plastic Beam Model). Computer verification data for all software are included in Appendix C. The finite element analyses discussed herein were independently verified by a LMITCO reviewer per the requirements of NQA-1 (Ref. 9).

\subsection{AEC Model}

In the AEC Model (Fig. 5 ), all beams have elastic material properties. The exterior columns, and other beam-like members in the structure that exhibit plastic behavior are represented with equivalent beams that consist of an elastic beam with nonlinear rotational springs at the end(s). All of the plastic behavior in these elements is concentrated in the rotational springs at the end of each element (see geometry in Fig. 6 ). The non-linear rotational springs were calibrated by AEC for each beam cross section type and are active only in rotation about the $\mathrm{X}$-axis. The spring stiffnesses also reflect the beam length. All other degrees of freedom at the connections are constrained to act together. The highest strains calculated in AEC's analysis were strains due to bending at the ends of exterior column elements.

Details of the AEC Model are discussed in Ref. 2. The boundary conditions used by AEC are summarized below:

(1) Nodes at the base of interior and exterior columns toward the north end were fixed in the vertical direction.

(2) Translational springs were used under exterior columns that potentially lift up (soft in the up direction, very stiff in the down direction).

(3) Translational springs were used under interior columns that potentially lift up (stiffness representative of the tie down connection in the up direction, very stiff in the down direction).

(4) All column bases are fixed in the horizontal directions.

(5) Non-linear vertical ( $Z$-direction) translational springs were used to model the interface between the fuel canister masses and the rack (see Fig. 7 ). In addition, all canister masses are restrained to move only in the vertical direction. Note that the dead weight of the canisters is supported by the floor. As the rack lifts, contact is made with the canisters after a vertical displacement of 0.4125 inches. Canister weight is then transferred to the rack. 
(6) Symmetry boundary conditions were applied to all nodes on the symmetry plane.

\subsection{Rotational Spring Model}

Details of the Rotational Spring Model are shown in Figs. 5-7. This model used beam cross-section properties from the AEC Model and is identical to the AEC Model with the following exceptions:

(1) The ABAQUS Standard program was used.

(2) The non-linear translational springs used for the canisters-rack interface were replaced with gap elements (Fig. 7 ).

(3) Weak spring and dashpot elements were used in parallel with the gap elements of item (2) above.

(4) The non-linear translational springs under the exterior columns were replaced with gap elements (note that these columns are not attached to the floor). Note that the column base nodes remain fixed in the horizontal directions.

Items 2 through 4 were necessary to attain convergence in the ABAQUS solutions. These are expected to have an insignificant effect on the analysis results.

Element types used include; 1) 2-node linear beams to represent beams and columns in the rack structure (ABAQUS type B31) , 2) 2-node translational springs to represent the interior column base support bolts and the canisters-rack interface (ABAQUS type SPRING2), 3) 2-node rotational springs as discussed above (ABAQUS type SPRING2), 4) 1-node lumped masses to represent the canisters (ABAQUS type MASS), 5) 2-node gaps as discussed above (ABAQUS type GAPUNI), and 6) 2-node dashpots to improve convergence (ABAQUS type DASHPOT2). A total of 3279 beam elements were used.

\subsection{Plastic Beam Model}

Details of the Plastic Beam Model are shown in Fig. 8 . Element types used are the same as those used for the Rotational Spring Model. A total of 9339 beam elements were used. The Plastic Beam Model is identical to the Rotational Spring Model with the following changes:

(1) All rotational springs were removed and replaced with constraints in all six degrees of freedom at the connection nodes.

(2) Plastic material properties were added to beams having rotational springs removed (see Fig. 8 ).

(3) Beam element mesh density was significantly increased near connections where plastic strain was predicted by the AEC and Rotational Spring Models. The mesh density needed to calculate accurate strain levels was determined using a simple beam model (Appendix A).

(4) The plastic beam cross sections for the tube-angles and the pipe-angles were approximated using ABAQUS box and pipe sections, respectively. The angle portion of these sections was ignored since it was not possible to represent the entire cross section 
of these members using ABAQUS plastic beams. A parametric study showed that ignoring the angles had a negligible effect on the maximum strains calculated for the column members. This approximation was conservative for calculating the strains in the tube-angles and pipe-angles since their full sections were not represented.

(5) The beam cross-section properties obtained from I-DEAS (Appendix B) were used for the elastic beam elements.

\subsection{Load Descriptions}

The analysis steps used for the ABAQUS analyses (the Rotational Spring and Plastic Beam Models) are listed in Table 3 . The magnitude of the loads and the locations applied were identical to those used by AEC in their ANSYS analysis.

Table 3 . Analysis Steps for ABAQUS Analyses

\begin{tabular}{|c|l|}
\hline $\begin{array}{c}\text { ANALYSIS } \\
\text { STEP }\end{array}$ & \\
\hline 1 & Gravity - Dead Weight \\
\hline 2 & N/S Seismic Loads on the Rack and the Canisters (exclusive of canister impact) \\
\hline 3 & Maximum N/S Canister Impact \\
\hline
\end{tabular}




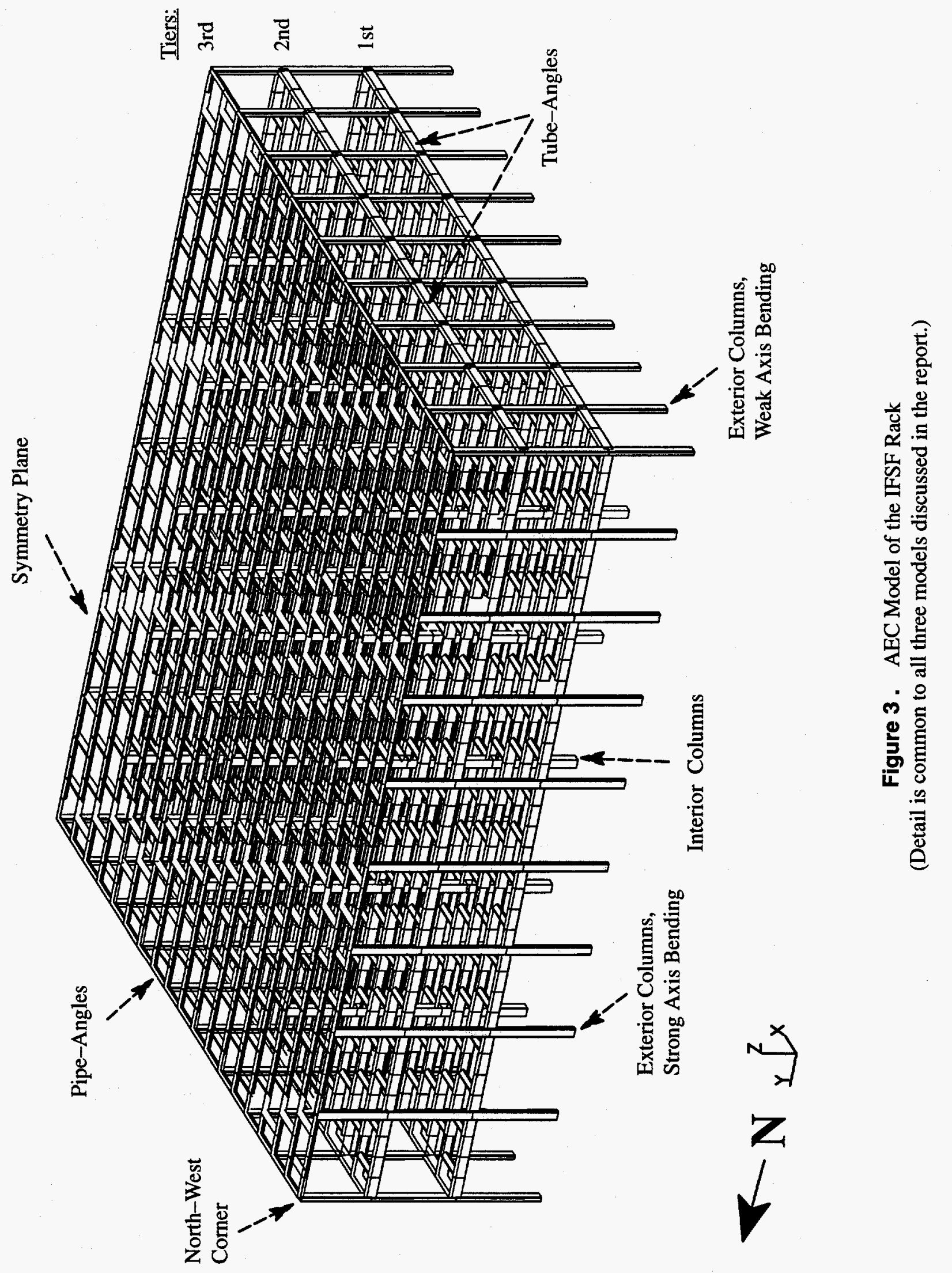


Figure 4 . Close-up View of NW Corner of IFSF Rack (from AEC Model) Showing Beam Detail, (Exterior Columns $=$ Grey, Interior Columns $=$ Red, Tube Angles $=$ Blue,

Pipe Angles $=$ Green, Top Angles $=$ Yellow, Diamonds $=$ Cyan $)$ 


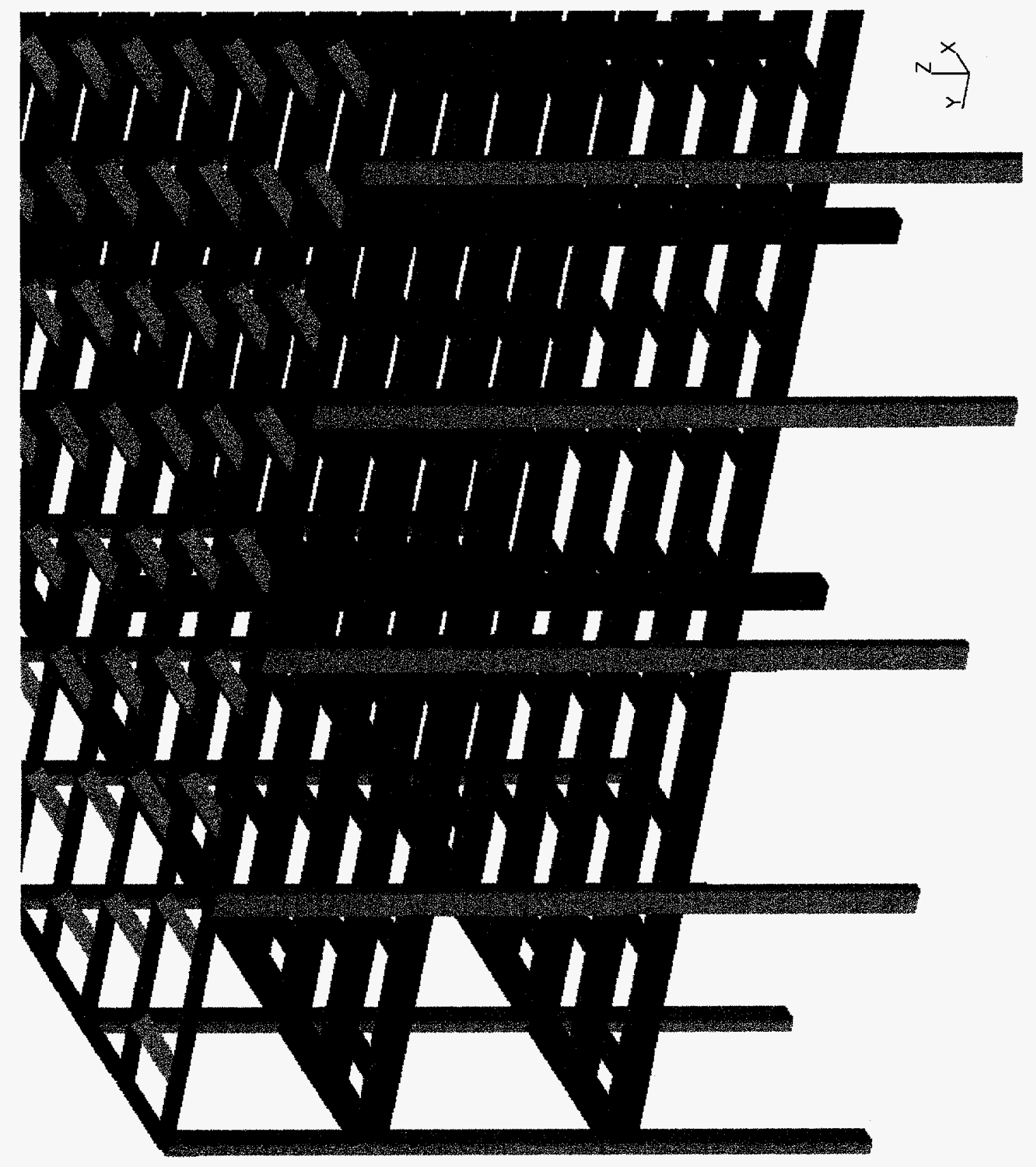




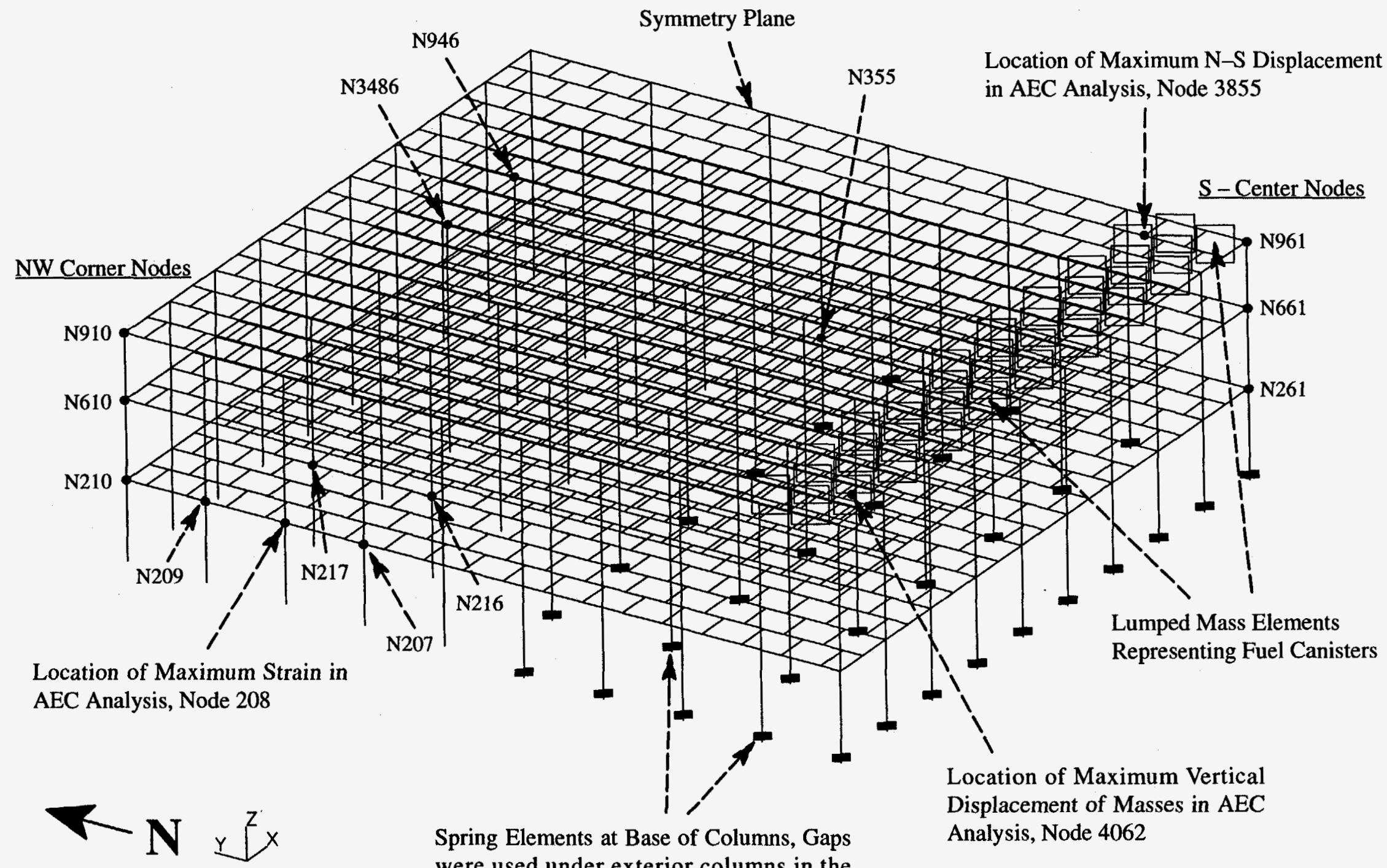
were used under exterior columns in the Rotational Spring and Plastic Beam Models

Figure 5. Details of AEC and Rotational Spring Models 


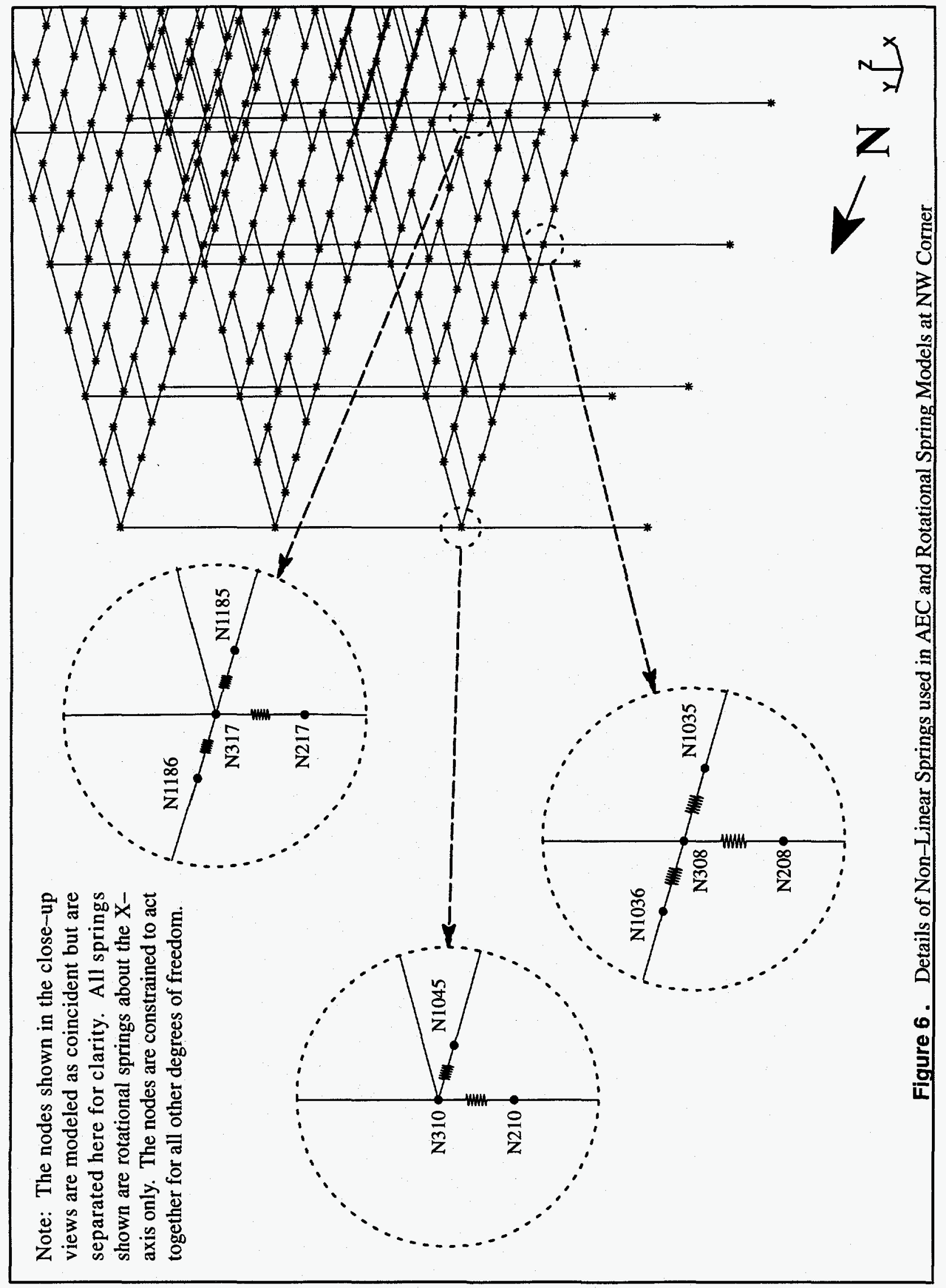




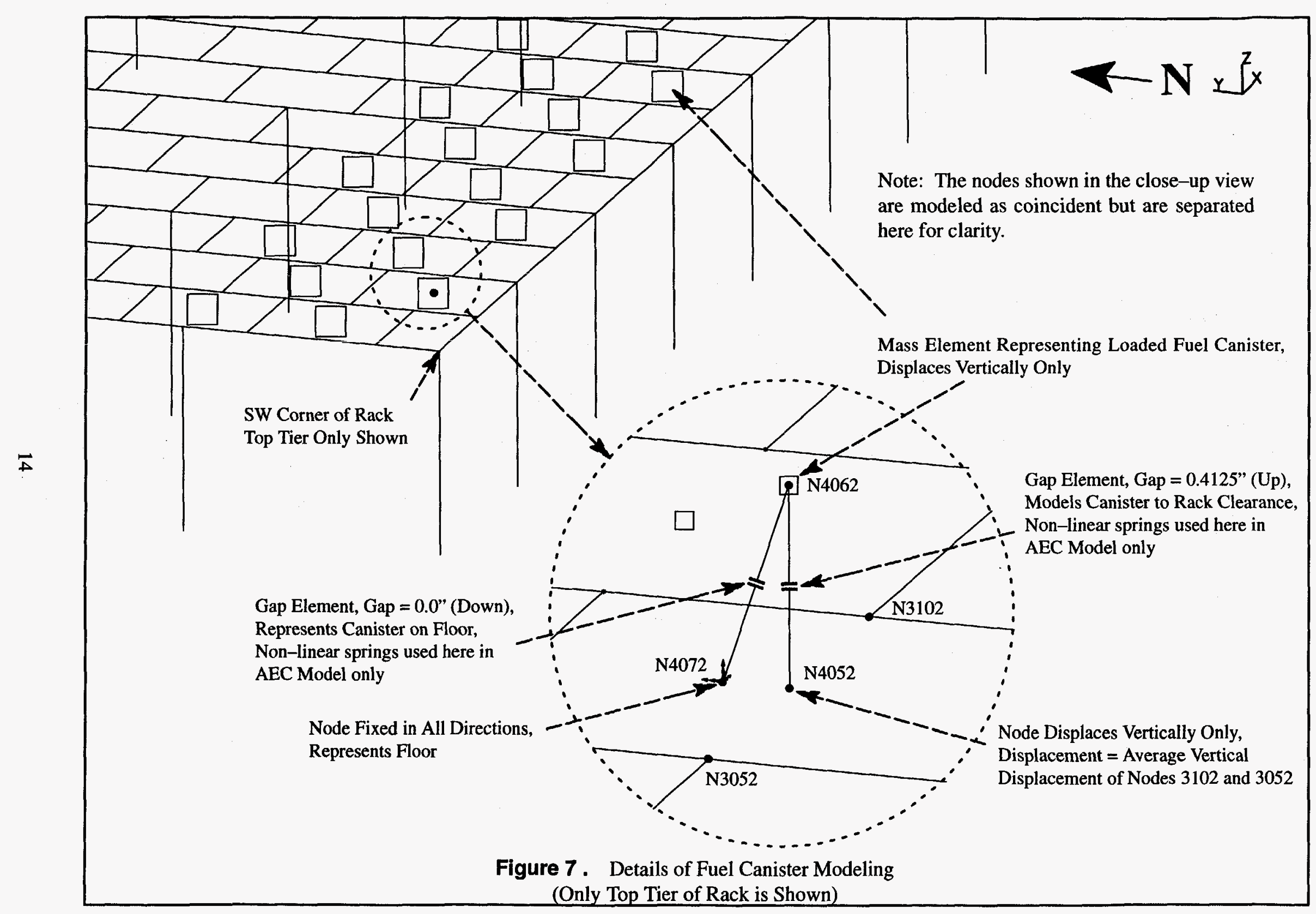




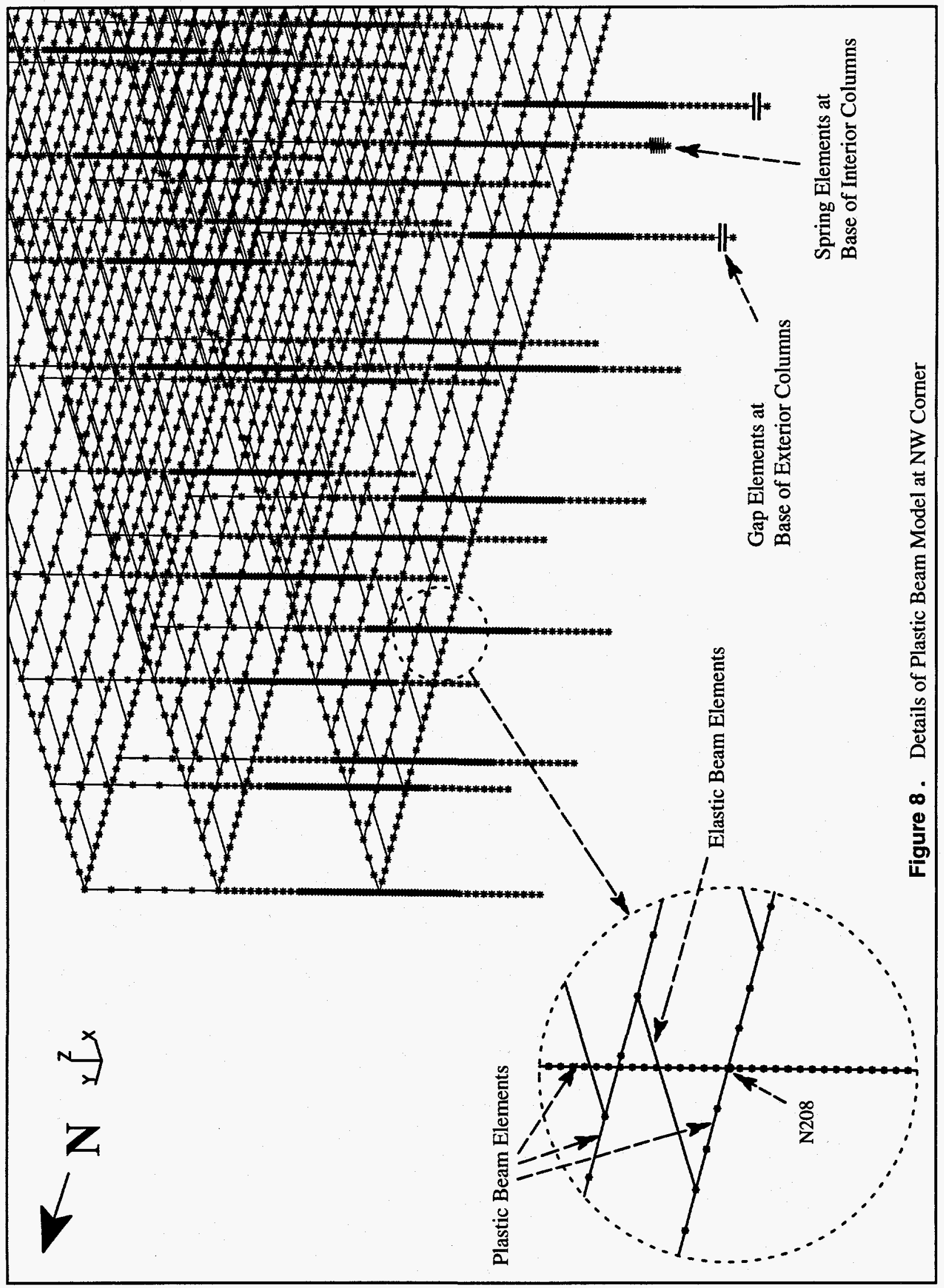




\section{ANALYSIS RESULTS}

\subsection{Comparison with AEC Model}

As previously discussed, AEC's ANSYS model (AEC Model) was converted to a corresponding ABAQUS model. This ABAQUS model (referred to as the Rotational Spring Model), like the AEC Model, employed rotational nonlinear springs to represent plastic behavior. This model was intended to replicate the AEC Model in all respects. To verify that the model was correctly transposed, comparisons were made between displacements calculated at several key locations (shown in Fig. 5 ). Among these is the location of maximum displacement, occurring in the top tier at node 3855 (see Fig. 5 ). The calculated displacements are compared in Table 4 , where it is shown that the Rotational Spring Model displacements are consistently slightly larger than the AEC Model displacements. The AEC Model displacements were taken directly from ANSYS computer output. The displacements compare quite closely, considering that the models contain nonlinear behavior and the programs do not use identical computational algorithms. The displacements calculated using the Plastic Beam Model are also shown in Table 4 and will be discussed below.

Fig. 9 presents deformed shapes from the AEC and Rotational Spring Models, respectively, viewed from the same perspective and using equal displacement magnifications. These serve to verify that the overall deformations for the two models are very comparable.

Table 4 . Comparison of Displacements for N-S Direction

\begin{tabular}{|c|c|c|c|}
\hline \multirow{2}{*}{$\begin{array}{c}\text { Nodes } \\
\text { (see Fig. 5) }\end{array}$} & \multicolumn{3}{|c|}{ Displacement, Inches } \\
\hline & AEC Model* & Rotational Spring Model & Plastic Beam Model \\
\hline $\begin{array}{l}\text { 3855, Maximum for } \\
\text { AEC Model, 3rd Tier }\end{array}$ & 1.81 & 1.92 & 2.70 \\
\hline $\begin{array}{c}\text { 208, Exterior Column, } \\
\text { 1st Tier }\end{array}$ & 0.92 & 1.14 & 1.38 \\
\hline $\begin{array}{c}\text { 216, Interior Column, } \\
\text { 1st Tier }\end{array}$ & 0.90 & 1.11 & 1.34 \\
\hline $\begin{array}{l}\text { 210, NW Corner, } \\
\text { 1st Tier }\end{array}$ & 0.92 & 1.14 & 1.38 \\
\hline $\begin{array}{l}\text { 610, NW Corner, } \\
\text { 2nd Tier }\end{array}$ & 1.31 & 1.47 & 2.01 \\
\hline $\begin{array}{l}\text { 910, NW Corner, } \\
\text { 3rd Tier }\end{array}$ & 1.60 & 1.74 & 2.50 \\
\hline $\begin{array}{l}\text { 261, S Center, } \\
\text { 1st Tier }\end{array}$ & 0.90 & 1.08 & 1.33 \\
\hline $\begin{array}{l}\text { 661, S Center, } \\
\text { 2nd Tier }\end{array}$ & 1.39 & 1.53 & 2.06 \\
\hline $\begin{array}{l}\text { 961, S Center, } \\
\text { 3rd Tier }\end{array}$ & 1.80 & 1.91 & 2.68 \\
\hline
\end{tabular}

* from calculation 6100-CA-04-CO-101, Ref. 2 

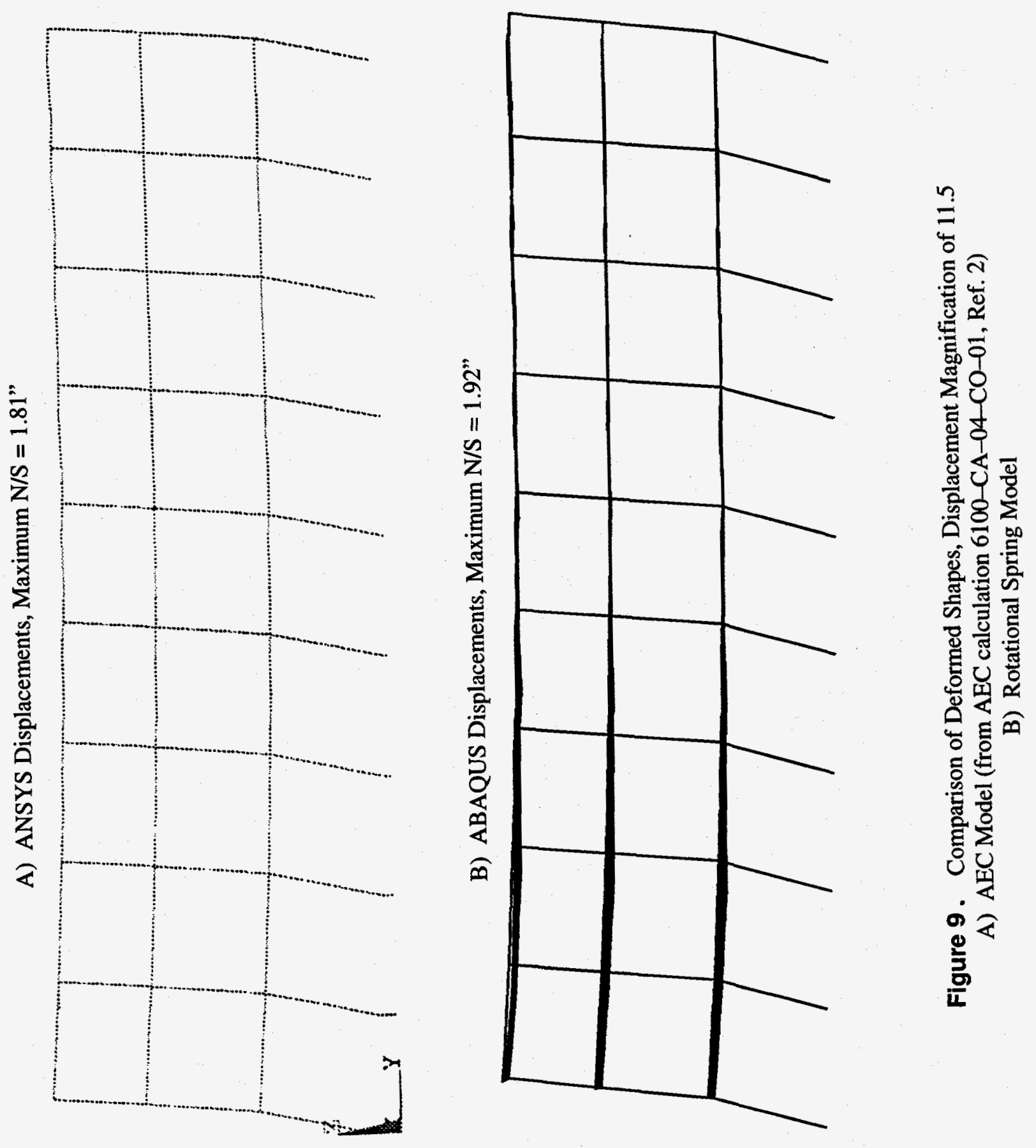
The only strains of significance reported by AEC in their analysis report (Ref. 2, Attachment 1) were in several of the exterior columns at the first tier level. These strains were tabulated in the form of demand-to-capacity (D/C) ratios, where the strain capacity at any point was taken to be $12 \%$. In the worst case, the $\mathrm{D} / \mathrm{C}$ ratio was listed as 0.77 , which translates to a strain value of $9.24 \%$. The moment-rotation relationships and corresponding strains for the rotational springs were developed by AEC using the RCCOLA computer program. Based on the output from the RCCOLA runs, this strain corresponds to a rotation in the spring of 0.192 radians for strong axis bending of the exterior column. This rotation would correspond to a displacement at the first tier (node 208, elevation $45.5 \mathrm{in}$.) of about (see drawing below):

$$
\delta=0.192(45.5)=8.74 \text { in }
$$

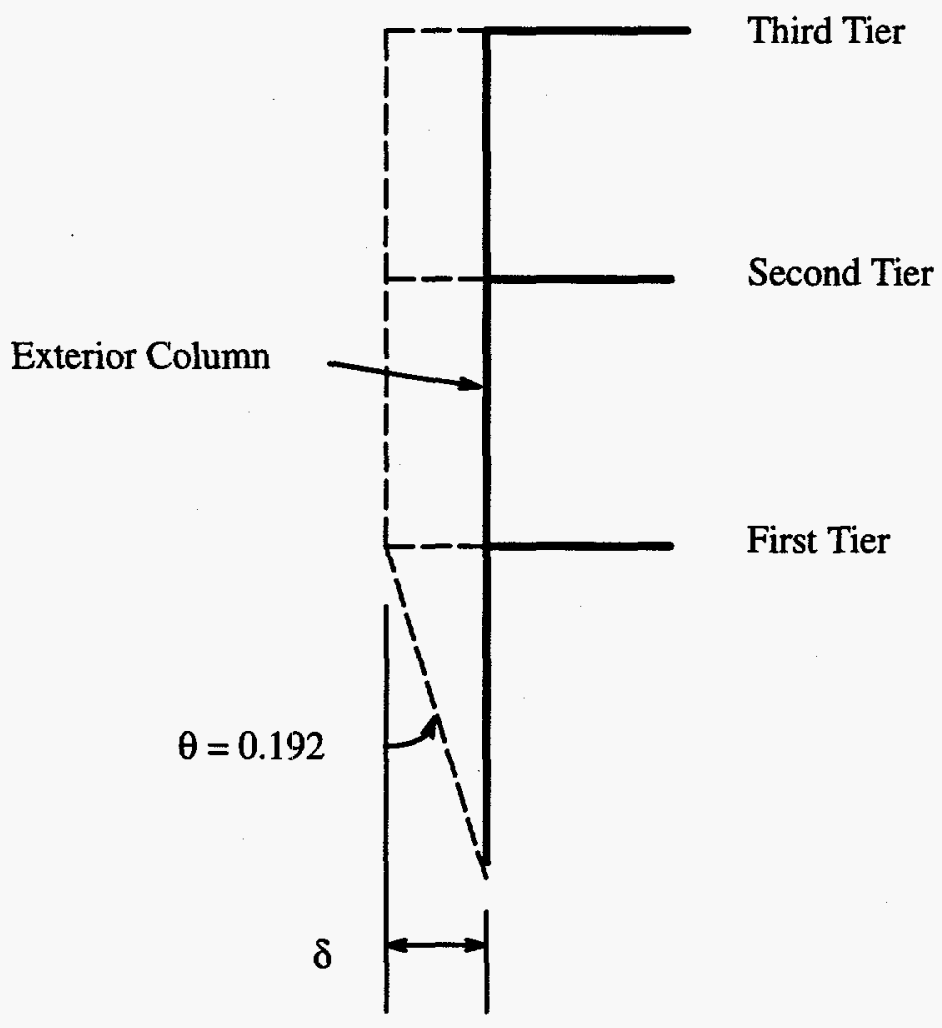

This is not consistent with the displacement calculated by ANSYS at this location of 0.92 in. (see Table 4). The strain level calculated by ABAQUS (Rotational Spring Model) for the same spring was $2.60 \%$. Using the RCCOLA output, this strain corresponds to a rotation in the spring of 0.0217 radians for strong axis bending. This rotation correspondis to a displacement at the first tier (node 208) of about: 


$$
\delta=0.0217(45.5)=0.99 \text { in }
$$

This is consistent with the displacements calculated by ANSYS and ABAQUS at node 208 (see Table 4). All other high strain values reported in Ref. 2 were similarly inconsistent with the calculated displacements, which is indicative of an error in transcription of results from the computer output. There was consistency in the calculated displacements between the Rotational Spring Model (ABAQUS) and the AEC model (ANSYS), and consistency between the ABAQUS strain values, RCCOLA computer output, and calculated displacements (for the two models). It was therefore concluded that the model was correctly transposed from ANSYS to ABAQUS.

\subsection{Strains, Displacements in Plastic Beam Model}

As previously discussed, an ABAQUS Plastic Beam Model was developed where all nonlinear rotational springs (of the Rotational Spring Model discussed in Sections 3.2 and 4.1) were removed. Plastic material properties were applied to all beams formerly having these rotational springs. In the Rotational Spring Model, all of the plastic material behavior in these beams was concentrated in the rotational springs. With the Plastic Beam Model, yielding of material occurs over some finite portion of the beam, resulting in a more realistic distribution of strain. This in turn was expected to reduce the maximum calculated values for strain.

The maximum strain calculated in the Rotational Spring Model was a bending strain in an exterior column, where it connects to horizontal beams at the first tier level. Table 5, which presents maximum strain values calculated in the models, shows that this maximum strain was calculated to be $2.60 \%$. Strains on the order of $2 \%$ were calculated for interior columns and tube angles. Also shown in Table 5 is that these peak strains were indeed reduced in the Plastic Beam Model to about $1 \%$ in the exterior columns, and well below $1 \%$ in all other locations.

Table 5 . Maximum Total Strains

\begin{tabular}{|c|c|c|c|c|}
\hline \multirow{2}{*}{ Beam Type } & \multicolumn{2}{|c|}{ Rotational Spring Model* } & \multicolumn{2}{c|}{ Plastic Beam Model } \\
\cline { 2 - 5 } & Spring Moment and Location & Strain, \% & Location & Strain, \% \\
\hline $\begin{array}{c}\text { Exterior Column, } \\
\text { Strong Axis }\end{array}$ & $\begin{array}{c}207.9 \text { in-k, } \\
\text { Nodes } 207,208,209\end{array}$ & 2.60 & Node 209 & 1.03 \\
\hline $\begin{array}{c}\text { Exterior Column, } \\
\text { Weak Axis }\end{array}$ & $\begin{array}{c}123.5 \text { in-k, } \\
\text { Node 210 }\end{array}$ & 1.64 & Node 210 & 0.33 \\
\hline Interior Column & $\begin{array}{c}422.8 \text { in }-k \\
\text { Nodes } 216,217\end{array}$ & 2.04 & Node 217 & 0.33 \\
\hline Pipe-Angles & $\begin{array}{c}45.6 \text { in -k } \\
\text { Node } 946\end{array}$ & 0.37 & Node 3486 & 0.34 \\
\hline Tube-Angles & $\begin{array}{c}270.5 \text { in -k } \\
\text { Node } 355\end{array}$ & 2.05 & Node 355 & 0.52 \\
\hline
\end{tabular}

* maximum spring moment converted to strain using AEC table, calculation 6100-CA-06 (2.1), Ref. 2

A plot showing strain contours for a portion of the Plastic Beam Model is presented in Fig. 10. The highest strain slightly exceeds $1 \%$ and is located at the first tier level of an exterior column. Fig. 11 
presents the deformed shape of the Plastic Beam Model viewed from the same perspective and using equal displacement magnification factors as used in Figs. 9 and 10 for the AEC and Rotational Spring Models, respectively. The displacements of Fig. 11 and Table 4 show that the displacements calculated with the Plastic Beam Model were somewhat higher than those from the Rotational Spring Model. This was attributable to the fact that yielding of material occurred over a portion of the length of the columns (in the Plastic Beam Model), so that a larger portion of the columns contributed to the global deformation of the structure. 
Figure 10. Maximum Strains Calculated in the Plastic Beam Model, Displacement Magnification of 11.5, View Similar to Figure 4 

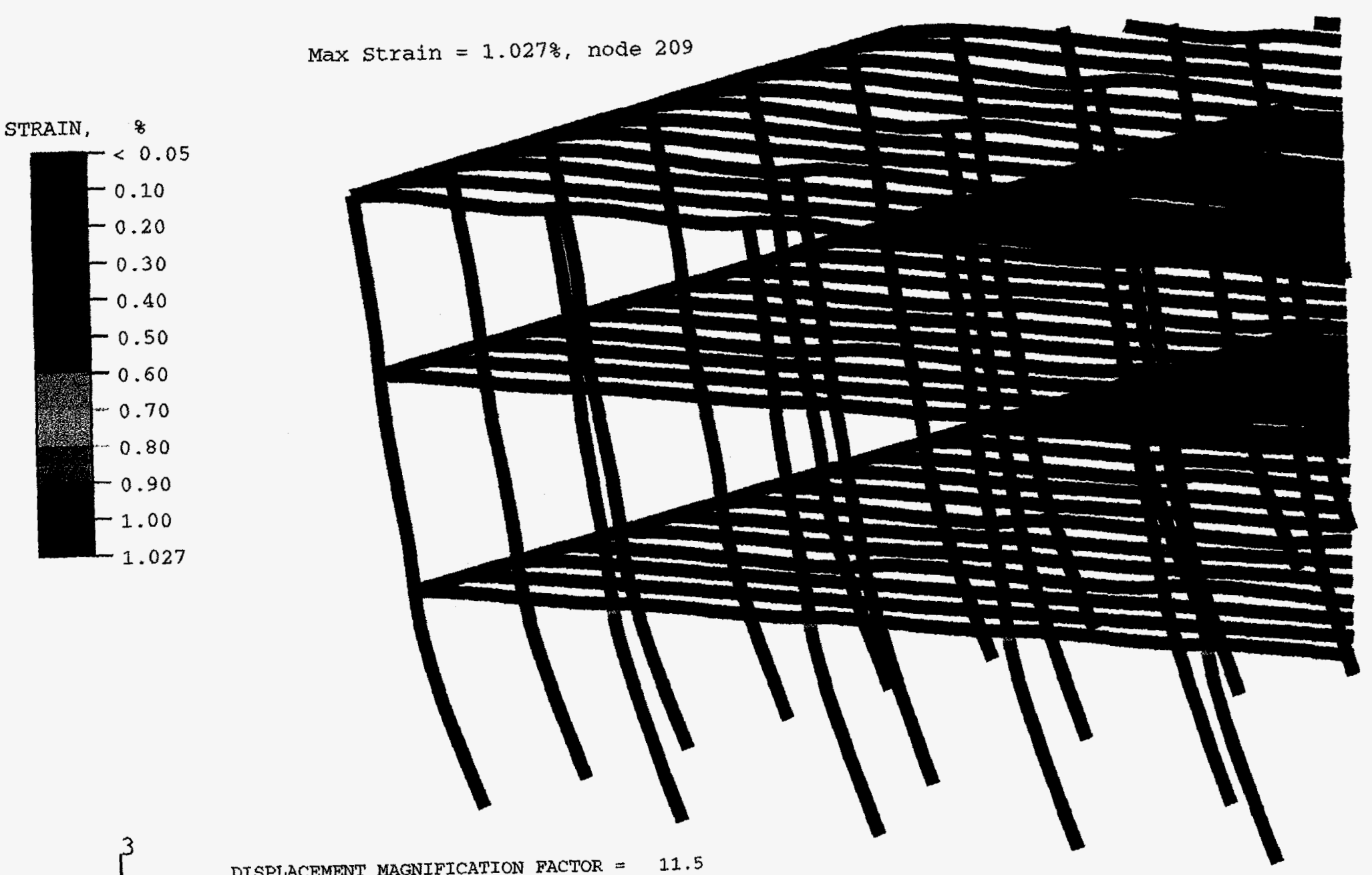

DISPLACEMENT MAGNIFICATION FACTOR $=11.5$

TIME COMPLETED IN THIS STEP 1.00 TOTAL ACCUMULATED TIME 4.00

ABAQUS VERSION: $5.5-3$ DATE: 04-MAR-97 TIME: $11: 50: 29$

STEP 4 INCREMENT 57 
Maximum displacement $=2.864$ at node 3501
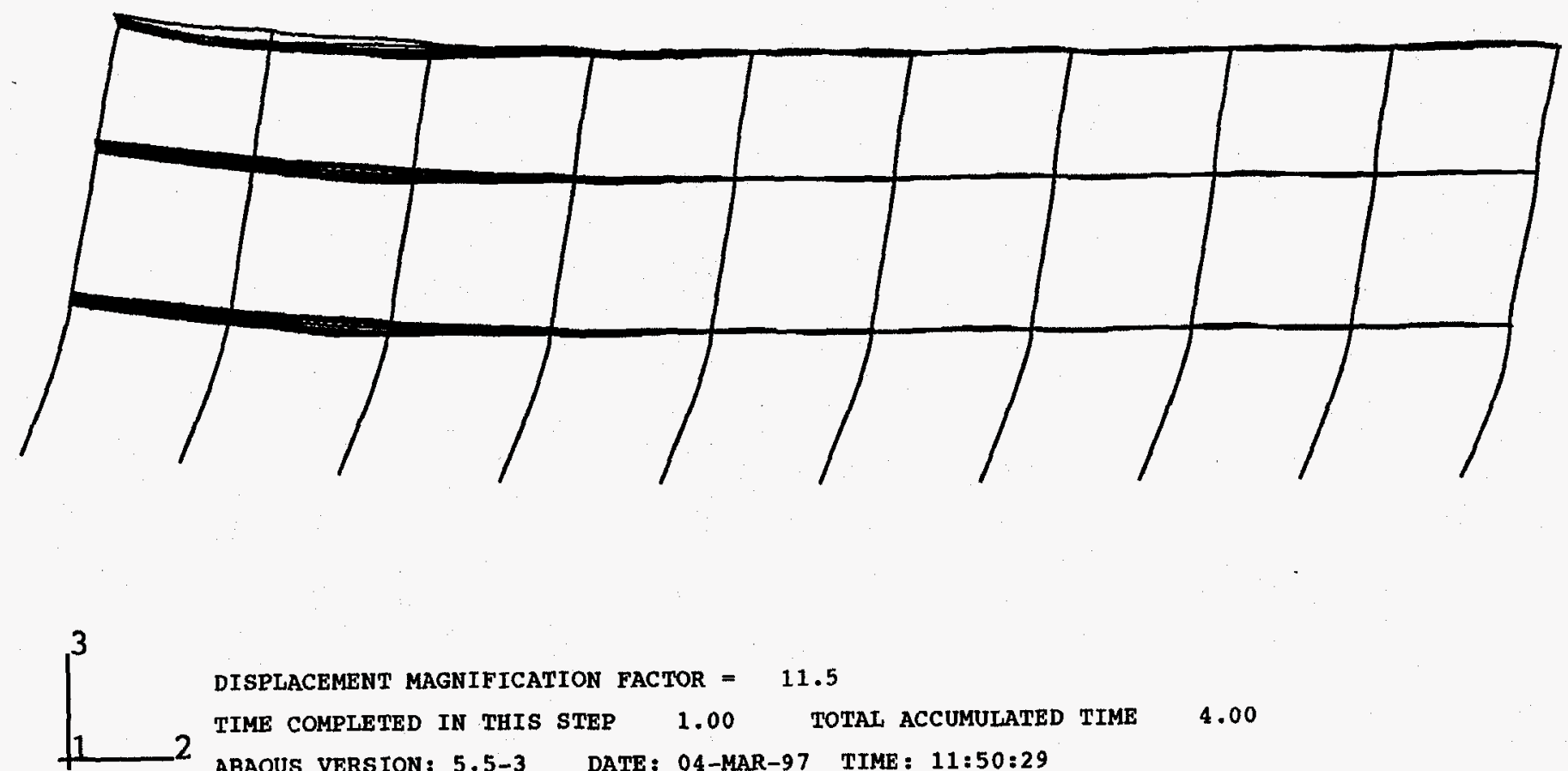

DISPLACEMENT MAGNIFICATION FACTOR $=11.5$

TIME COMPLETED IN THIS STEP 1.00 TOTAL ACCUMULATED TIME 4.00

ABAQUS VERSION: 5.5-3 DATE: 04-MAR-97 TIME: 11:50:29

STEP 4 INCREMENT 57

Figure 11. Plastic Beam Model Deformed Shape, Displacement

Magnification of 11.5 


\subsection{Evaluation of Calculated Strain Levels}

The Criteria Application Document (Appendix of Ref. 2) for analysis of the IFSF rack identifies ANSI/AISC N690-1994 (Ref. 5) as a governing specification for determining acceptability of the rack. This standard specifies an allowable ductility factor, $\mu$, for extreme and abnormal loads to be

$$
\mu \leq 20.0
$$

This ductility limit applies to flexure in closed sections such as those of the IFSF rack. The ductility factor is defined as the ratio of permitted strain to the strain at yield in the member. Strain at yield is determined as follows:

$$
\epsilon_{y}=\frac{F_{y}}{E}=\frac{36}{29 \times 10^{3}}=0.00124
$$

Here, $F_{y}$ and $E$ are the yield stress and modulus of elasticity for A36 steel (in ksi), respectively. This results in a permitted strain of

$$
\epsilon_{\text {all }}=20(0.00124)=0.025=2.5 \%
$$

The calculated strains in the Plastic Beam Model lie within this limit, meaning that the strains in the IFSF rack meet the project acceptance criteria.

The allowable ductility factor, $\mu$, as used in ANSI/AISC N690-1994 is a local or member ductility. The system ductility ratio (as defined in Ref. 10) is another convenient measure of structural response to seismic loads and is related to the energy absorption capacity of the entire structure. This ratio can be estimated by:

$$
\mu_{\text {system }}=\frac{U_{\text {max }}}{U_{\text {yield }}}
$$

where:

$U_{\max }=\quad$ Maximum displacement in rack

$U_{\text {yield }}=\quad$ Maximum displacement in rack when strain in any member first reaches yield $(0.124 \%)$ 
Newmark and Hall (Ref. 11) state that system ductility capacities for steel frame structures can be expected to range from 4 to 8 . The system ductility for the IFSF rack was calculated using the Plastic Beam Model. The maximum N-S displacement in the model at full load was 2.70 inches (node 3855, Table 4 ). The maximum $\mathrm{N}-\mathrm{S}$ displacement at the same node when the strain in any member first reached yield was 1.15 inches. The system ductility, then, is estimated to be:

$$
\mu_{\text {system }}=\frac{2.70}{1.15}=2.35
$$

The value is under the capacity range given by Newmark and Hall. Therefore, steel frame structures typically have ductility capacities greater than that required of the IFSF Rack.

\subsection{East-West Loading}

As mentioned in Section 1, the North-South model was selected for detailed analysis because it was reported to give the maximum strain value in AEC's analysis. At completion of the analysis of the North-South Rotational Spring Model, though, it was realized that AEC's reported strain values were not necessarily consistent with the calculated displacements. An examination of the displacements from AEC's East-West analysis revealed that the maximum displacements from that model exceeded maximum displacements of the North-South model by about $50 \%$. To estimate the effect that these higher displacements would have on the strain values, the impact loading on the North-South Rotational Spring Model was continually increased until the maximum displacement matched that of AEC's East-West model (2.68 in.). This displacement was amplified slightly since the Rotational Spring Model calculates slightly higher displacements than the AEC Model (see Table 4). Accordingly, the Rotational Spring Model was run until the maximum displacement (at the top tier level) reached

$$
\delta=2.68 \frac{(1.92)}{(1.81)}=2.85 \text { in }
$$

The ratio 1.92/1.81 accounts for the small calculational differences between ABAQUS and ANSYS (at the top tier level). At the displacement of $2.85 \mathrm{in}$., the corresponding maximum moment in the nonlinear springs for the exterior columns (at the first tier level) was

$$
M=214.5 \text { kip }- \text { in }
$$

Based on the computer output from AEC's RCCOLA runs, this moment corresponds to a strain of $3.76 \%$. Results for the North-South Plastic Beam Model showed that the maximum strain was reduced from $2.60 \%$ to $1.03 \%$ for the Plastic Beam Model vs. the Rotational Spring Model. This reduction in maximum strain was the result of strain distribution in the plastic beams. Scaling from these results, strain distribution can similarly be expected to reduce the maximum strain for the East-West model from $3.76 \%$ to about $1.49 \%$.

The maximum strain for the East-West model can also be estimated by considering the maximum calculated displacement at the first tier level from AEC's analysis (1.33 in.). A displacement of 1.33 in. at the first tier corresponds to a rotation in the rotational spring of an exterior column of about 


$$
\theta=\frac{1.33}{45.5} \frac{(1.14)}{(0.92)}=0.0362 \text { radians }
$$

The ratio 1.14/0.92 accounts for the small calculational differences between ABAQUS and ANSYS (at the first tier level). Based on AEC's RCCOLA output, this rotation corresponds to a strain of 3.64\%. Again scaling from results of the North-South model, strain distribution in an East-West plastic beam model would be expected to reduce this strain to about $1.44 \%$. This is consistent with the $1.49 \%$ strain estimated above.

Though a complete East-West analysis using plastic beam elements was not performed, the results above indicate that such an analysis would calculate a maximum strain for the exterior columns of about $1.5 \%$. Since this is within the acceptance criterion of $2.5 \%$, the rack structure is considered to be acceptable for East-West loading. 


\section{TUBULAR BEAM BEHAVIOR - LITERATURE SEARCH}

It was shown in Section 4 that the strain levels calculated in the seismic analysis for the IFSF fuel storage rack meet governing Code ductility requirements. However, recognizing that failures occurred in the connections of welded steel moment frame structures during the Northridge earthquake (Refs. 12 and 13), a literature search was conducted for test data relating to the ductility of connections of tubular structures. The purpose for this study was to further assure that the IFSF rack connections have sufficient ductility to accommodate the strain levels calculated.

As part of the literature search, the following structural research institutions and code organizations were contacted regarding the availability of applicable test results:

(1) Powell Structural Research Laboratories, Univ. of California, San Diego

(2) Univ. of Wisconsin, Milwaukee

(3) Washington State Univ.

(4) Ferguson Structural Laboratory, Univ. of Texas, Austin

(5) Earthquake Engineering Research Center, Univ. of California, Berkeley

(6) SAC Joint Venture (Structural Engineers Association of California, Applied Technology Council, California Universities for Research in Earthquake Engineering)

(7) ANSU/AISC N690-1994 Code Committee

It was found that essentially all experimental work performed on tubular structures having members of a size comparable to those of the IFSF rack has been focused on offshore oil platform structures. In those applications, the tubular members are generally braces that are welded to main structural members (chords). Tubular members are selected for these braces because of their favorable buckling characteristics (among other advantages). Published test data that determines the ductile capacity of the connections in even these structures is very limited. Where data is available, the failure in any particular connection is dependent on parameters such as brace-to-chord diameter ratio, diameter-to-thickness ratios, material properties, length of members involved, and the basic configuration of the joint. Furthermore, these connections are not totally representative of the IFSF rack, since the rack has rectangular tubular members vs. the round tubes normally used in platform structures. An extensive search did not produce test results that are fully representative of the IFSF rack.

Test results that were found for tubular structures indicate that joints of the IFSF rack should easily exhibit the ductility needed to sustain the strain levels calculated in the stress analysis of the rack. In the tests of Ref. 14, tubular steel braces (struts) were subjected to severe cyclic axial loadings. As with members of the IFSF rack, the struts in these tests were fabricated of A36 steel. They were of a size (4-in. diameter) comparable to the members of the IFSF rack. Struts having diameter to thickness (D/t) ratios of 33 and 48 were tested to evaluate the effect of $D / t$. The former meets guidelines of the American Petroleum Institute (API, Ref. 15) for a fully compact section capable of developing its full plastic capacity through large inelastic deformations $\left(\mathrm{D} / \mathrm{t}<1300 / \mathrm{F}_{\mathrm{y}}\right)$. Most importantly, the test results showed that large strains (axial plus bending) accumulated before the members buckled. For example, strains in members having $\mathrm{D} / \mathrm{t}=33$ reached 0.15 and 0.35 for pinned end and fixed end conditions, respectively. Higher strains were achieved in the compact section $(D / t=33)$ than in the section having $\mathrm{D} / \mathrm{t}=48$. It is noted that the columns and main beams of the IFSF rack have effective $D / t$ ratios of about 15 , meaning that they should have capacity to achieve large strains prior to buckling.

In the tests of Ref. 16, a planar offshore platform tubular frame model was subjected to shake table excitation. The frame was a three-tier structure approximately $18 \mathrm{ft}$ high and $6 \mathrm{ft}$ wide. The IFSF rack is 
a three-tier structure that is approximately $11 \mathrm{ft} \mathrm{high}$. The tubular braces in the frame were fabricated from A513 mild steel. The braces were of 2.5 to 3.5 -in. diameter, with wall thicknesses of 0.046 to $0.083 \mathrm{in}$. The $\mathrm{D} / \mathrm{t}$ ratios for the braces ranged from 36 to 54 , which are considerably higher than those of the tubular members of the IFSF rack structure. The braces were welded to 8-in. diameter, 0.188-in. thick columns. The frame was exposed to a series of seismic inputs with peak table accelerations of up to $1.228 \mathrm{~g}$. For tests having a peak input acceleration of $0.58 \mathrm{~g}$, there was tensile and compressive yielding in the weakest braces $(D / t=54)$, but there was no visible buckling. For tests having a peak input acceleration of $1.228 \mathrm{~g}$, there was cornpressive buckling and tensile yielding in the weakest braces $(\mathrm{D} / \mathrm{t}=$ 54). Test results showed that the bending strains in these thin-walled tubular members exceeded $1.5 \%$ prior to buckling. It is noted that these strains do not include the axial component. The stronger tubular braces $(D / t=36)$ did not buckle during the tests. Since the members of the IFSF rack have D/t ratios of about 15 , these test results indicate that they should sustain strain levels well above those calculated in the analysis.

Significant efforts have been published (Refs. 17 - 19) on performing detailed finite element analysis on welded tubular connections which account for material and geometric nonlinearity, and which apply a fracture criterion for cases where fracture is the dominant mechanism of failure. These methods are intended to provide an alternative to testing programs for predicting failure in these connections. In these methods, damage in the connections is often measured in terms of strain level. It is recognized that the plastic strain at rupture in a typical joint is less than the strain to rupture in the uniaxial tension case. These detailed analytical methods cannot be readily applied in assessing the tubular members of the IFSF rack. Based on all considerations discussed above, the strain levels in the IFSF rack are considered to be low enough that a detailed finite element analysis of a connection is not necessary.

The members in the IFSF rack are medium-sized closed compact sections, unlike the large open sections that experienced fractures in the Northridge earthquake. The test results above for compact closed sections indicate that the connections of the IFSF rack should sustain the strain levels calculated.

Paragraph 7.10.5 of Refs. 11 and 12 provides interim guidelines for moment frame tubular systems in the aftermath of the Northridge earthquake. The recommendation given therein is that "... a thorough analysis of the structural system should be made to determine what potential plastic rotation demand would be required on the connections." The analysis reported here meets this recommendation and demonstrates that the IFSF rack meets the ductility criteria identified in the ANSI/AISC N690-1994 standard. 


\section{CONCLUSIONS}

Advanced Engineering Consultants (AEC) previously performed a finite element analysis of the IFSF Storage Rack (subjected to seismic loads) and reported significant strain levels in several members of the rack. Plastic behavior in beam members was modeled by AEC using equivalent beams, which consisted of an elastic beam with nonlinear rotational springs at its end(s). Using this method, all of the plastic behavior was concentrated in the rotational springs at the ends of the element. This modeling approach should give a reasonable representation of overall rack behavior, but can be expected to overestimate strain levels at the ends of the equivalent beams. The highest strains calculated in AEC's analysis were strains due to bending at the ends of exterior column elements at the first tier level of the rack.

The purpose for the study herein was to refine the accuracy of the calculated strain levels, and then to assess the acceptability of the refined strain values. The nonlinear rotational springs of the AEC Model (solved using the ANSYS program) were replaced with a refined mesh of beam elements having elastic-plastic material properties representative of A36 steel. This new model was then used to perform an analysis of the IFSF rack (subjected to seismic loading) using the ABAQUS program. The same loads were applied to this model as were used in AEC's analysis. This analysis was expected to produce more realistic maximum strains in key locations than were calculated in AEC's analysis.

The following conclusions were reached:

(1) Maximum strain calculated using the Plastic Beam Model was $1.03 \%$ in an exterior column at the first tier level. The rack members have closed cross-sections and are of medium size. Based on ANSI/AISC N690-1994 criteria, a strain of $2.5 \%$ is considered to be an acceptable strain limit for these members. Since the calculated strains lie within this limit, the conclusion was reached that the rack structure is acceptable and meets the project acceptance criteria.

(2) To verify the conversion of the AEC Model to the ABAQUS program, the ABAQUS model (Rotational Spring Model) was also solved without modifying any of AEC's equivalent beams. This analysis solved the same problem as solved by AEC, but was performed on ABAQUS instead of ANSYS. The verification was made by comparing results from this solution to results obtained by AEC. Results compared were rack displacements at various key locations in the rack structure and global deformed shapes for the two models. The conversion to ABAQUS was verified to be correct.

(3) Though experimental data for tubular structures representative of the IFSF rack is scant, results of the literature review were consistent with the acceptability of the $2.5 \%$ strain limit.

(4) Based on the calculated displacements from AEC's East-West model together with the reductions in maximum strain levels associated with the strain distribution in the ABAQUS Plastic Beam Model, maximum strain for East-West loading was estimated to be $1.5 \%$. Since this value lies within the acceptance criteria, the IFSF rack is also acceptable for East-West seismic loading.

(5) The analysis described in this report was performed only to investigate the strains in the IFSF rack. AEC's analysis stands as the analysis of record for the rack. 


\section{REFERENCES}

1 Aerojet Nuclear Co. Drawings, 1375-CPP603-M17 to M23, Serial Nos. 154867 - 154873

2 Advanced Engineering Consultants Inc., Nonlinear Seismic Analysis and Evaluation of the IFSF Fuel Storage Rack, L. E. Malik, AEC Job No. 6100, San Francisco, CA, June 1996.

3 Swanson Analysis Systems, Inc., Houston, PA, ANSYS 5.1, 1996.

4 Hibbitt, Karlsson, and Sorenson, Inc., Providence, Rhode Island, ABAQUS 5.5, 1994.

5 American Institute of Steel Construction, Specification for the Design, Fabrication, and Erection of Steel Safety-Related Structures for Nuclear Facilities, ANSI/AISC N690-1994, 1994.

6 R. L. Brockenbrough, Structural Alloys Handbook. A 36 Steel, Purdue Research Foundation, West Lafayette, Indiana, 1994.

7 American Society for Testing and Materials, 1993 Annual Book of ASTM Standards, 1993.

8 Structural Dynamics Research Corp., Milford, OH, I-DEAS, Master Series 2.1, 1995.

9 American Society of Mechanical Engineers, Quality Assurance Requirements for Nuclear Facility Applications, ASME NQA-1-1994, July 1994

10 R. P. Kennedy and S. A. Short, Seismic Analysis, UCRL-15742, DOE Natural Phenomena Hazards Mitigation Conference, Oct. 1985.

11 N. M. Newmark and W. J. Hall, Earthquake Spectra and Design, EERI, 1982.

12 Federal Emergency Management Agency, Interim Guidelines: Evaluation, Repair, Modification and Design of Welded Steel Moment Frame Structures, FEMA 267, 1995.

13 Federal Emergency Management Agency, Interim Guidelines Advisory No. 1, Supplement to FEMA 267, FEMA-267A, March 1997.

14 V. A. Zayas, E. P. Popov, S. A. Mahin, Cyclic Inelastic Buckling of Tubular Steel Braces Earthquake Engineering Research Center, Report No. UCB/EERC - 80/16, June 1980.

15 American Petroleum Institute, Recommended Practice for Planning, Designing, and Constructing Fixed Offshore Platforms Dallas, Texas, Ninth Edition, November 1977; Tenth Edition, March 1979.

16 Y. Ghanaat, R. W. Clough, Shaking Table Tests of a Tubular Steel Frame Model Earthquake Engineering Research Center, Report No. UCB/EERC - 82/02, January 1982.

17 W. F. Cofer, J. S. Jubran, Analysis of Welded Tubular Connections Using Continuum Damage Mechanics, J Structural Engineering, Vol. 118, No. 3, March 1992.

18 W. F. Cofer, K. M. Mill, A Finite Element Technique for the Ultimate Strength Analysis of Tubular Joints, Engineering Computations, Vol. 9, No. 3, June 1992.

19 J. S. Jubran and W. F. Cofer, Finite-Element Modeling of Tubular Joints. I. Numerical Results and II. Design Equations, J Structurall Engineering, Vol. 121, No. 3, March 1995. 


\section{Appendix A}

\section{Misc. Calculations}

Appendix A includes:

1. Verification of ABAQUS Plastic Beam Elements for Strain Calculation

2. Listing of ABAQUS Input for Plastic Beam Verification 
A-2 


\section{VERIFICATION OF ABAQUS PLASTIC BEAM ELEMENTS FOR STRAIN CALCULATION}

\section{Plastic Strain Calculation}

In AEC's analysis of the IFSF rack structure, exterior columns and other beam-like members that exhibit plastic behavior were represented with equivalent beams that consist of an elastic beam with nonlinear rotational springs at its end(s). AEC used the RCCOLA computer program to calculate the $M-\theta$ (moment - rotation) relationships for the non-linear rotational springs used in their equivalent beams. The program also calculated the maximum strain at the end of the column. An ABAQUS model of a single plastic beam has been developed here to (1) verify that it would produce basically the same strain as did the RCCOLA program for the same moment loading, and (2) determine an appropriate mesh density for plastic beam elements in the high-strained column members of the IFSF Rack Plastic Beam Model. The beam modeled spans between a pinned support at one end and a vertical support at the other as shown below:

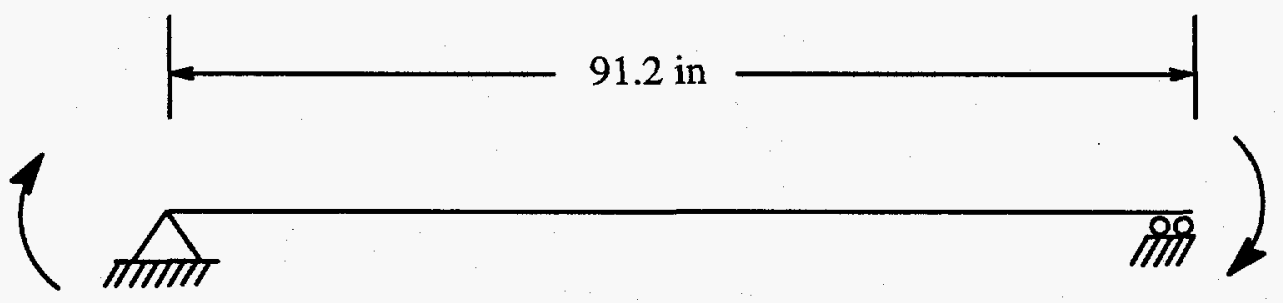

The RCCOLA program divides this beam into a number of discrete intervals. From equilibrium, the program calculates the bending moment at each point separating the intervals. It creates a stress distribution across the beam cross-section that balances the bending moment. The program then calculates strains and a curvature at each point based on the beam cross-section and material properties. The strain values in the cross-section vary with distance from the neutral axis at that point. The curvature at a point along the beam is proportional to the strains in the cross-section at that point. The amount of flexural rotation occurring in each discrete interval is readily determined from the curvatures at each end of the interval. The total rotation at the end of the beam is calculated by summing contributions from the discrete intervals.

To be consistent with AEC's RCCOLA calculations, the beam in the ABAQUS model was given a length (91.2 in.) equal to twice the height of a column member in the first tier. Since this member has zero moment at its center, it is equivalent to a $45.6 \mathrm{in}$. column member having a zero moment at one end. One-half the beam analyzed, then, represents a column member of the first tier. Material properties were set equal to those used by AEC as follows:

Yield Stress

Youngs Modulus

Strain at Onset of Strain Hardening

Strain Hardening Modulus

Maximum Stress
$36 \mathrm{ksi}$

$29000 \mathrm{ksi}$

0.014

$118.28 \mathrm{ksi}$

$58 \mathrm{ksi}$ 
Beam cross-sectional properties were input to match those of the cross-section of the exterior columns. Results for weak-axis bending are compared to those obtained from AEC's RCCOLA run below:

\begin{tabular}{c|c|c} 
Applied Moment $(\mathrm{k}-\mathrm{in})$ & Strain, RCCOLA & Strain, ABAQUS \\
\hline 128.08 & 0.0299 & 0.0256 \\
\hline 158.35 & 0.100 & 0.107 \\
\hline 178.91 & 0.150 & 0.162 \\
\hline 191.20 & 0.195 & 0.196
\end{tabular}

Results for strong-axis bending for the same beam are as follows:

\begin{tabular}{c|c|c} 
Applied Moment $(\mathrm{k}-\mathrm{in})$ & Strain, RCCOLA & Strain, ABAQUS \\
\hline 210.05 & 0.0299 & 0.0230 \\
\hline 256.01 & 0.100 & 0.107 \\
\hline 286.84 & 0.148 & 0.163 \\
\hline 306.12 & 0.192 & 0.198
\end{tabular}

The calculated strains compare favorably, indicating that the ABAQUS program should calculate appropriate strain levels for elements modeled as plastic beam elements.

\section{Mesh Considerations}

In the ABAQUS analysis above, the sample beam was divided into a uniform 100 -element mesh. When the mesh was reduced to a uniform 30 elements, the strain for the $158.35 \mathrm{k}$-in moment (weak-axis bending) decreased from 0.107 to 0.097 . This indicates that a 30 -element mesh should give reasonable results. In the analysis of the IFSF rack where plastic beams were used, the portion of an exterior column in the first tier was divided into 35 elements. Of these, 25 elements were concentrated into the upper half of the column, where strain levels are highest.

An ABAQUS input file for the 100-element plastic beam model is included in this Appendix. 


\section{LISTING OF ABAQUS INPUT FOR PLASTIC BEAM VERIFICATION}

*HEADING

SAMPLE BEAM PROBLEM, WEAK AXIS BENDING

*PREPRINT,ECHO=NO,HISTORY $=$ YES

*NODE

$1,0 ., 0 ., 0$.

$101,91.2,0.0$

*NGEN

1,101

*ELEMENT,TYPE=B21,ELSET=BEAMS

$1,1,2$

*ELGEN,ELSET=BEAMS

$1,100,1,1$

*MATERIAL,NAME=A36

*ELASTIC

29.E+6,0.3

*DENSITY

7.317E-4

*PLASTIC

36000.,0.

$36100 ., 0.0128$

$58000 ., 0.200$

*BEAM SECTION,MATERIAL=A36,SECTION=BOX,ELSET=BEAMS

$5 ., 2.5, .259, .259, .259, .259$

"BOUNDARY

$1,1,2$

101,2

«STEP,NLGEOM,INC=100

*STATIC

$0.005,1$,

*RESTART,WRITE,FREQUENCY=1

*CLOAD

$1,6,158350$.

$101,6,158350$.

*EL PRINT,ELSET=BEAMS

1,2,3,4,5

S11,MISES

E11

"END STEP 


\title{
Appendix B
}

\section{BEAM SECTION DATA}

\begin{abstract}
Appendix B contains cross sectional data for the beams used in the ABAQUS Plastic Beam Model analysis. Cross sectional data was calculated and sketched using I-DEAS (Ref. 8); data listed is output from ABAQUS (Ref. 4); and the units are inches. The centroidal axes are shown as $\mathrm{Y}$ and $\mathrm{Z}$ in the sketches. These correspond to axes 1 and 2, respectively, in the ABAQUS listings.
\end{abstract}




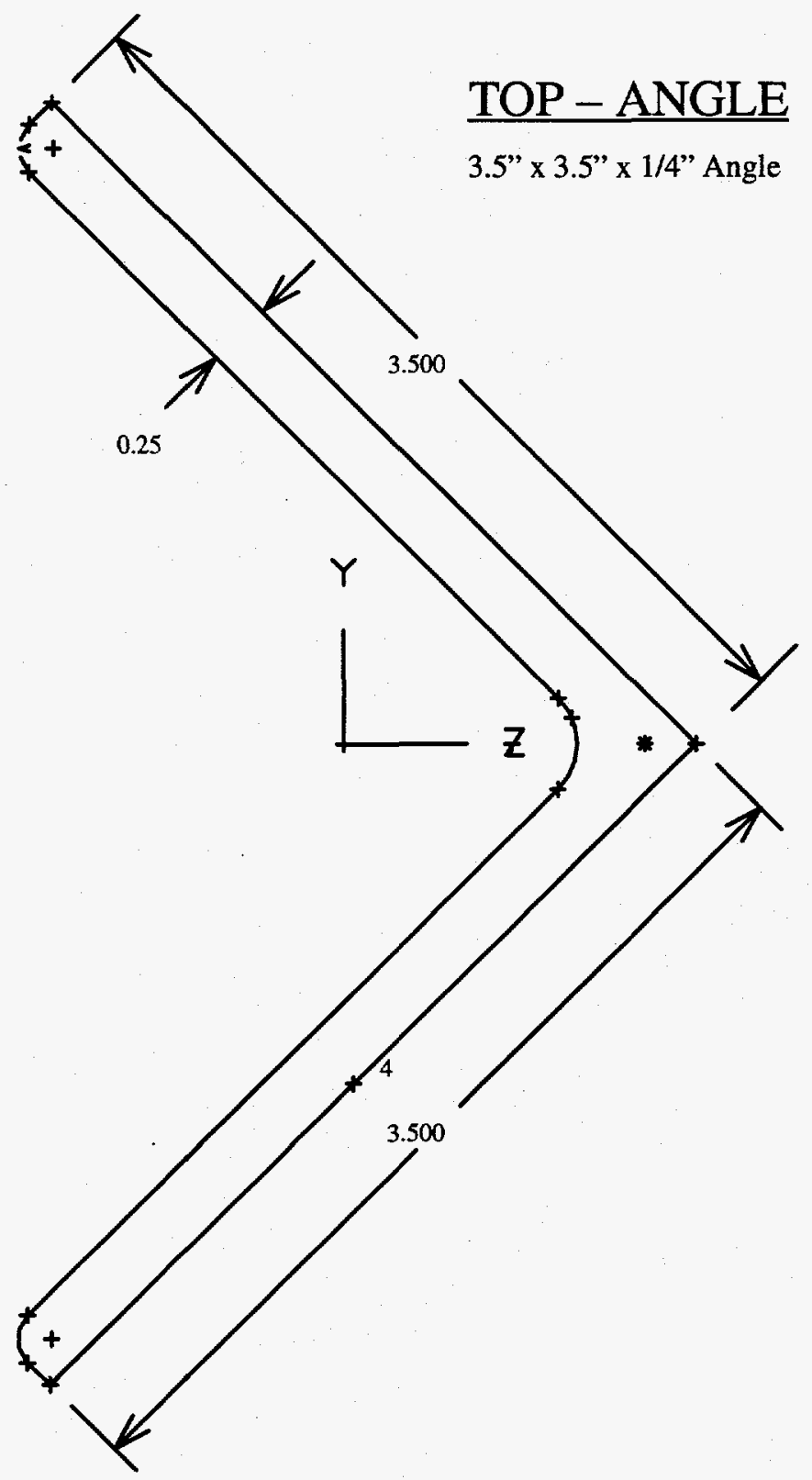

PROPERTIES:

AREA $=1.693720$

MOMENT OF INERTIA I(11)

MOMENT OF INERTIA I(22)

$=0.8113200$

PRODUCT OF INERTIA I(12)

$=3.163410$

POLAR MOMENT OF INERTIA I(11)+

TORSION CONSTANT

$=0.0000000 \mathrm{E}+00$

CENTROID COORDINATES $(1,2)$

$=3.7106100 \mathrm{E}-02$

SHEAR CENTER COORDINATES $(1,2)$

$=(0.0000000 \mathrm{E}+00,0.0000000 \mathrm{E}+00)$ $=(0.0000000 \mathrm{E}+00,1.157686)$

DENSITY $\quad 8.98606 \mathrm{E}-07$ 


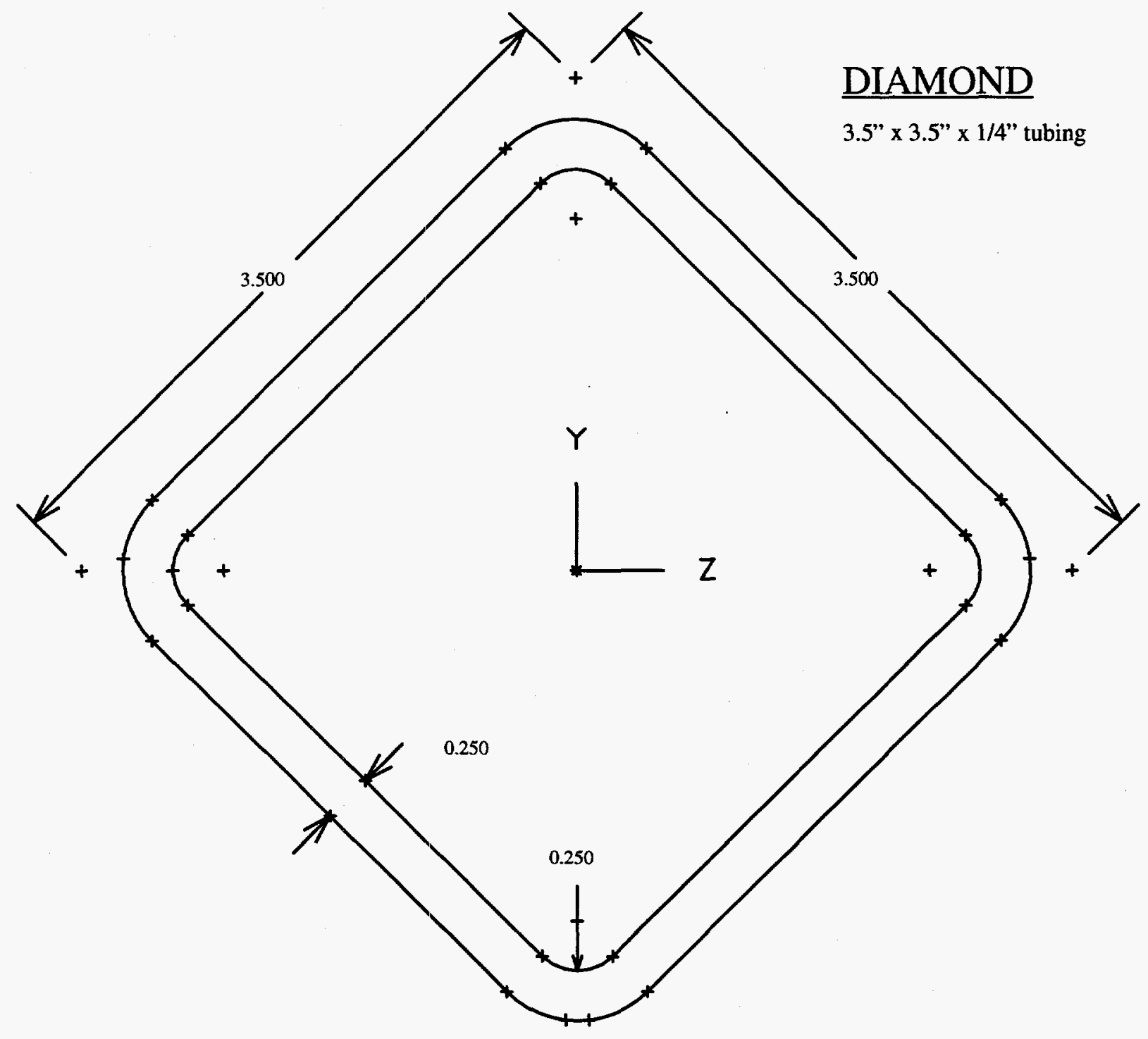

PROPERTIES:

$\begin{array}{lrl}\text { AREA } & 3.087470 & \\ \text { MOMENT OF INERTIA I }(11) & = & 5.282900 \\ \text { MOMENT OF INERTIA II(22) } & = & 5.282890 \\ \text { PRODUCT OF INERTIA I (12) } & = & 0.0000000 \mathrm{E}+00 \\ \text { POLAR MOMENT OF INERTIA I }(11)+\mathrm{I}(22) \quad= & =10.56579 \\ \text { TORSION CONSTANT } & = & 8.925210 \\ \text { CENTROID COORDINATES }(1,2) & =(0.0000000 \mathrm{E}+00,0.0000000 \mathrm{E}+00) \\ \text { SHEAR CENTER COORDINATES }(1,2) & =(0.0000000 \mathrm{E}+00,0.0000000 \mathrm{E}+00) \\ \text { DENSITY } & 7.33859 \mathrm{E}-07\end{array}$




\section{EXTERIOR COLUMN}

2.5 " x 5" x 0.259 " tubing

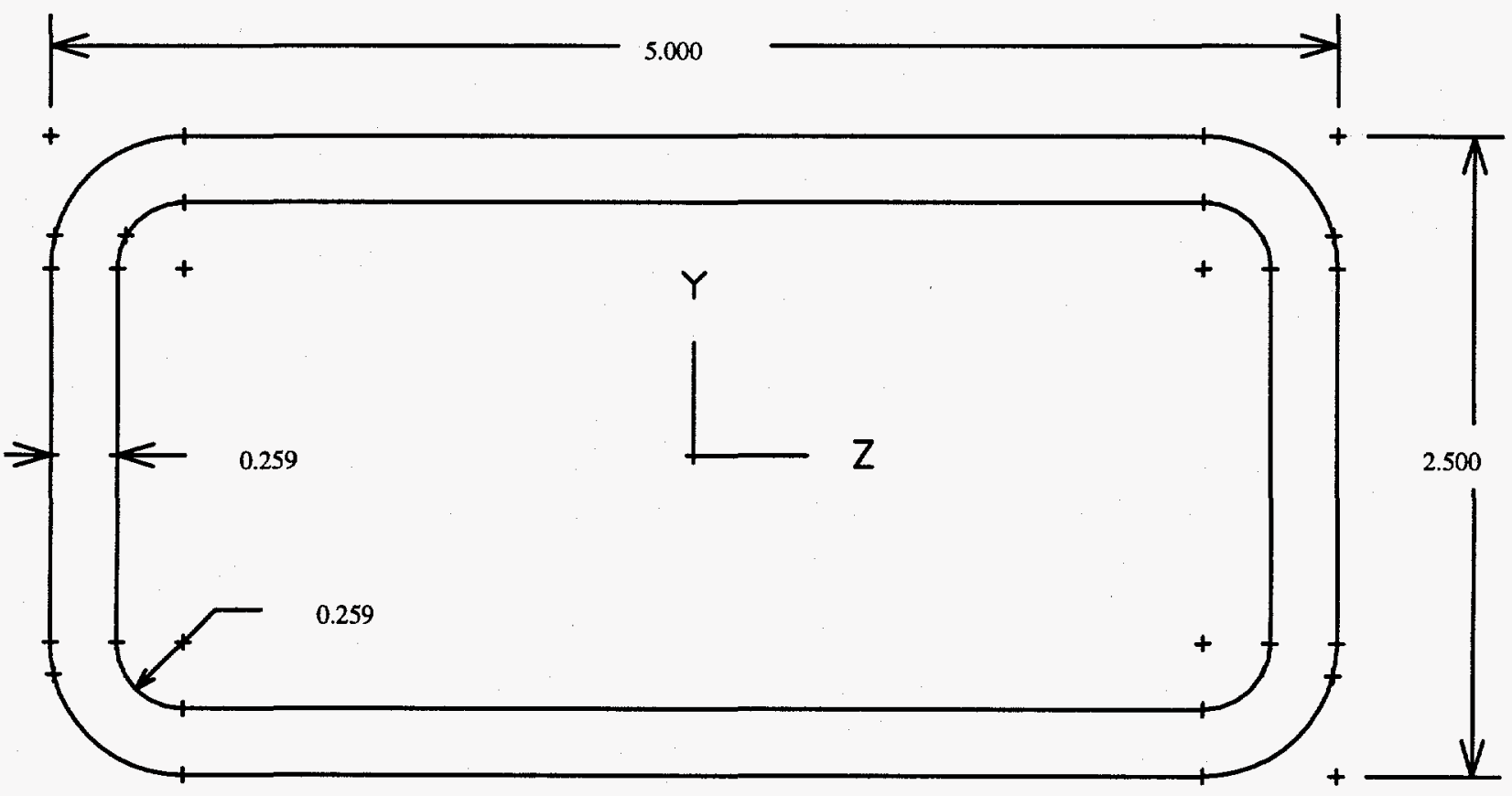

PROPERTIES:

AREA

$=3.443810$

MOMENT OF INERTIA I(11)

MOMENT OF INERTIA I(22)

$=10.12580$

PRODUCT OF INERTIA I(12)

$=3.350690$

POLAR MOMENT OF INERTIA I $(11)+\mathrm{I}(22)=13.47649$

TORSION CONSTANT

$=8.699080$

CENTROID COORDINATES $(1,2)$

$=(0.0000000 \mathrm{E}+00,0.0000000 \mathrm{E}+00)$

SHEAR CENTER COORDINATES $(1,2)$

$=(0.0000000 \mathrm{E}+00,0.0000000 \mathrm{E}+00)$

DENSITY $1.04808 \mathrm{E}-06$ 


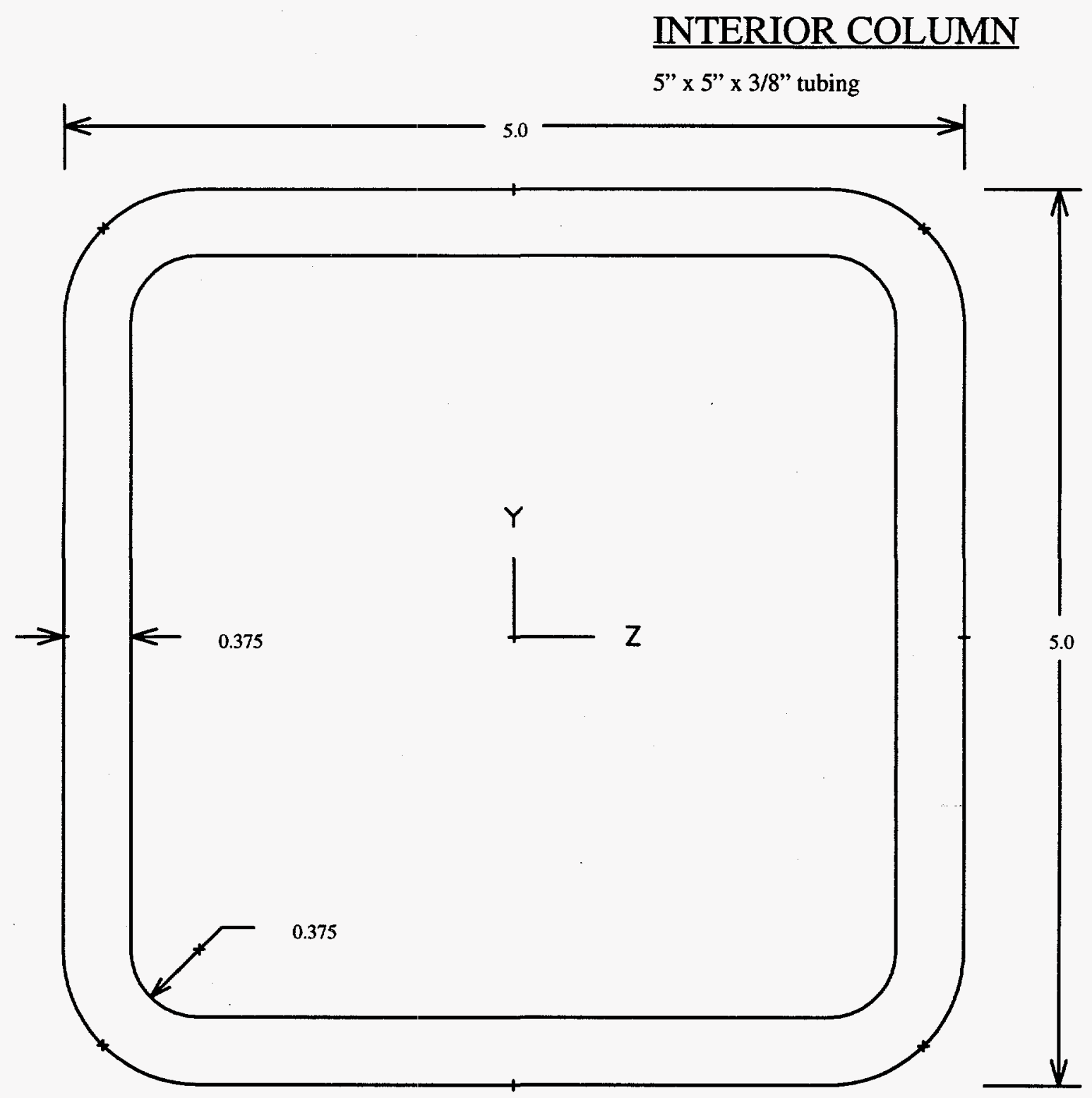

PROPERTIES:

AREA

$=6.575360$

MOMENT OF INERTIA I(11)

MOMENT OF INERTIA I(22)

PRODUCT OF INERTIA I(12)

21.20360

$=21.20360$

POLAR MOMENT OF INERTIA I(11)+I(22) $\quad=42.40720$

TORSION CONSTANT

$=44.95020$

CENTROID COORDINATES $(1,2)$

$=(0.0000000 \mathrm{E}+00,0.0000000 \mathrm{E}+00)$

SHEAR CENTER COORDINATES $(1,2) \quad=(0.0000000 \mathrm{E}+00$, $0.0000000 \mathrm{E}+00$ )

DENSITY 7.33859E-07 


\section{PIPE - ANGLE}

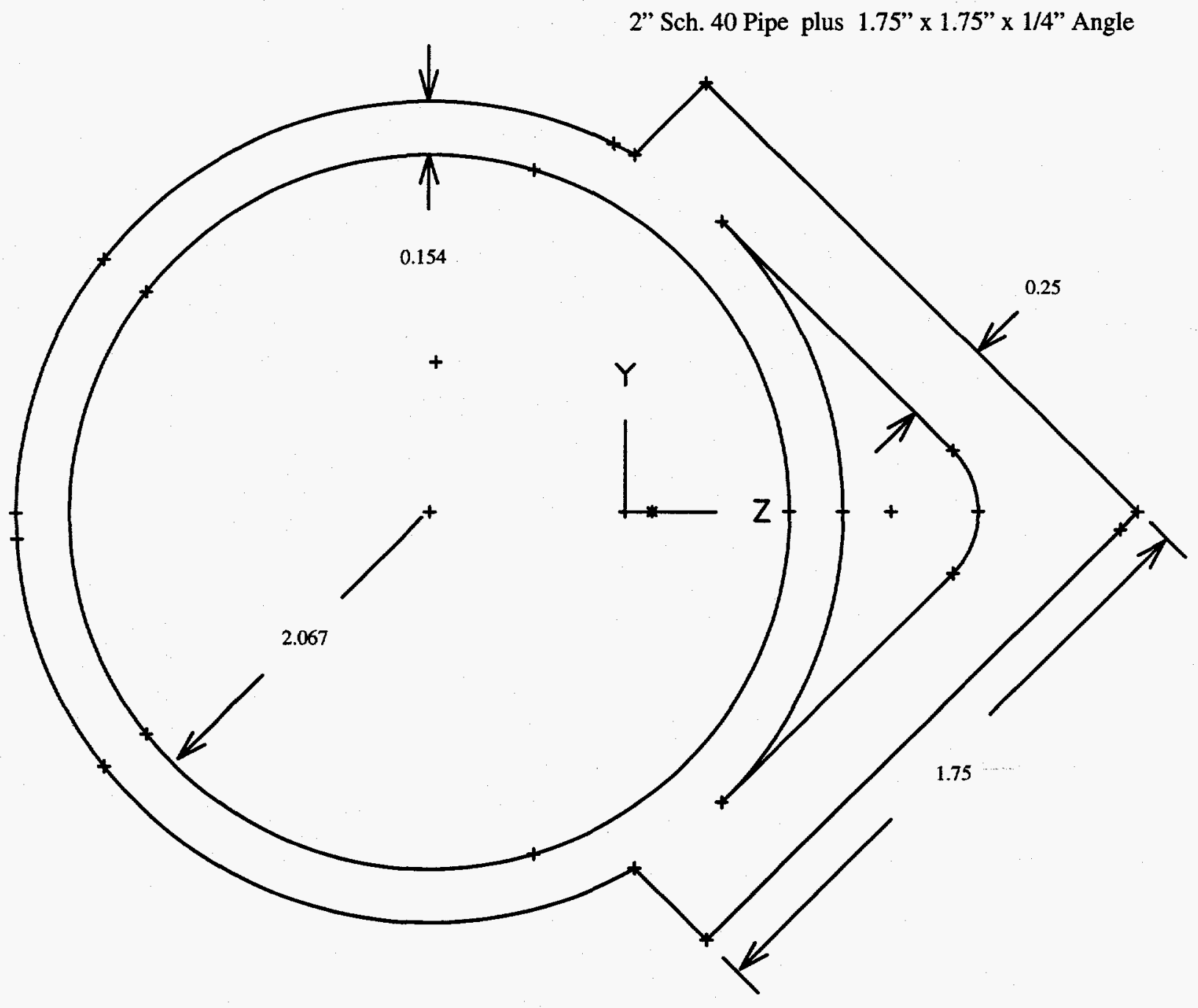

PROPERTIES:

AREA $=1.909860$

MOMENT OF INERTIA I(11)

MOMENT OF INERTIA I(22)

$=1.539120$

PRODUCT OF INERTIA I(12)

$=1.033810$

$=0.0000000 \mathrm{E}+00$

POLAR MOMENT OF INERTIA I $(11)+\mathrm{I}(22)=2.572930$

TORSION CONSTANT

$=2.113030$

CENTROID COORDINATES $(1,2)$

SHEAR CENTER COORDINATES $(1,2)$

$$
\begin{aligned}
& =(0.0000000 \mathrm{E}+00,0.0000000 \mathrm{E}+00) \\
& =(0.0000000 \mathrm{E}+00,7.8188820 \mathrm{E}-02)
\end{aligned}
$$

DENSITY $8.98606 \mathrm{E}-07$ 


\section{TUBE - ANGLE}

2.5 " x 5" x 0.259 " tubing plus 1.75 " x 1.75 " x $3 / 16$ " Angle

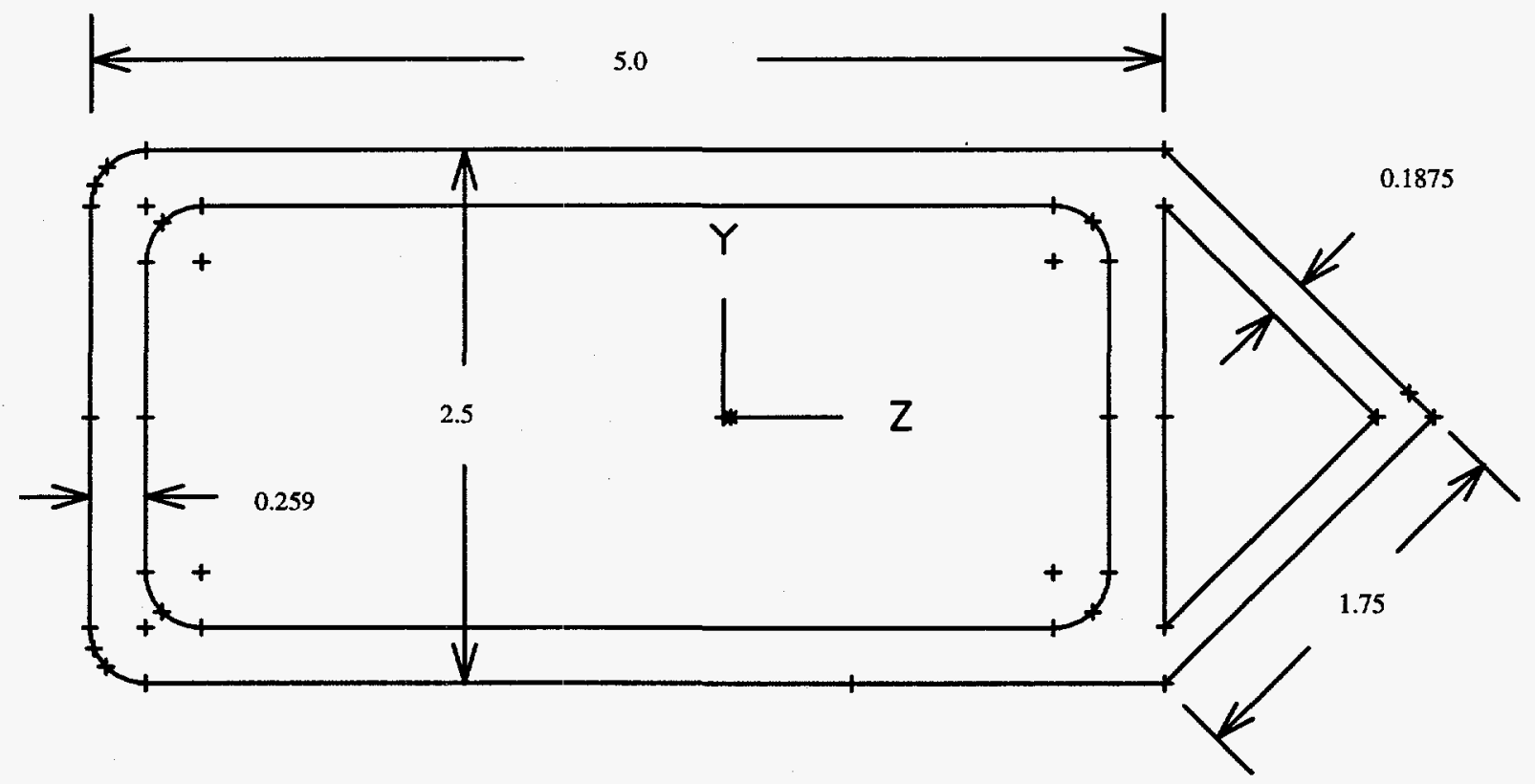

PROPERTIES:

AREA $=4.242840$

MOMENT OF INERTIA I(11)

MOMENT OF INERTLA I(22)

$=16.06050$

PRODUCT OF INERTIA I(12)

$=3.864550$

POLAR MOMENT OF INERTIA I $(11)+\mathrm{I}(22)=19.92505$

TORSION CONSTANT.

$=10.63040$

CENTROID COORDINATES $(1,2)$

$=(0.0000000 \mathrm{E}+00,0.0000000 \mathrm{E}+00)$

SHEAR CENTER COORDINATES $(1,2)$

$=(5.6282220 \mathrm{E}-04,3.4505000 \mathrm{E}-02)$

DENSITY 7.33859E-07 


\section{Appendix C}

\section{Computer Verification and Sample Data}

Appendix C includes:

1. Documentation of computer configuration and verification

2. Sample Listing of ABAQUS finite element input data 
C-2 


\section{COMPUTER CONFIGURATION AND VERIFICATION}

The following documentation presents the traceability for computer programs used in the analysis reported here.

Report Title: Evaluation of Strain Levels in the IFSF Rack

Author: W. D. Richins \& G. K. Miller Date: June 1997

Program Used: I-DEAS Version: Master Series 2.1

Computer Used: $\quad$ DEC ALPHA Station ASHTON

Verification Manual/Test Problem Manual/Example Manual:

-SDRC I-DEAS Verification Manual, Structural Dynamics Research Corporation, Milford, $\mathrm{OH}$

C. C. O'Brien letter to Applied Mechanics, Jan. 24, 1995, "Verification of SDRC I-DEAS MS 1.3C Software for the DEC Platform," CCO-03-95.

Program Used:

Computer Used:
ABAQUS Standard Version: 5.5-3

DEC ALPHA Stations ASHTON and CASPER

Verification Manual/Test Problem Manual/Example Manual:

ABAQUS Example Problems Manual, Hibbitt, Karlsson, and Sorenson, Inc., Providence, Rhode Island, 1995.

W. D. Richins letter to Applied Mechanics, "Verification of HKS ABAQUS 5.5-3 for DEC ALPHA Workstations," LMITCO letter WDR-07-96, Oct. 17, 1996. 
2. SAMPLE INPUT FILES FOR ABAQUS STANDARD ANALYSIS 
The following lists sample input data for ABAQUS Standard used in this report. The node coordinates, element definitions, and set definitions have been removed due to the volume of material.

\section{INPUT DATA, ROTATIONAL SPRING MODEL}

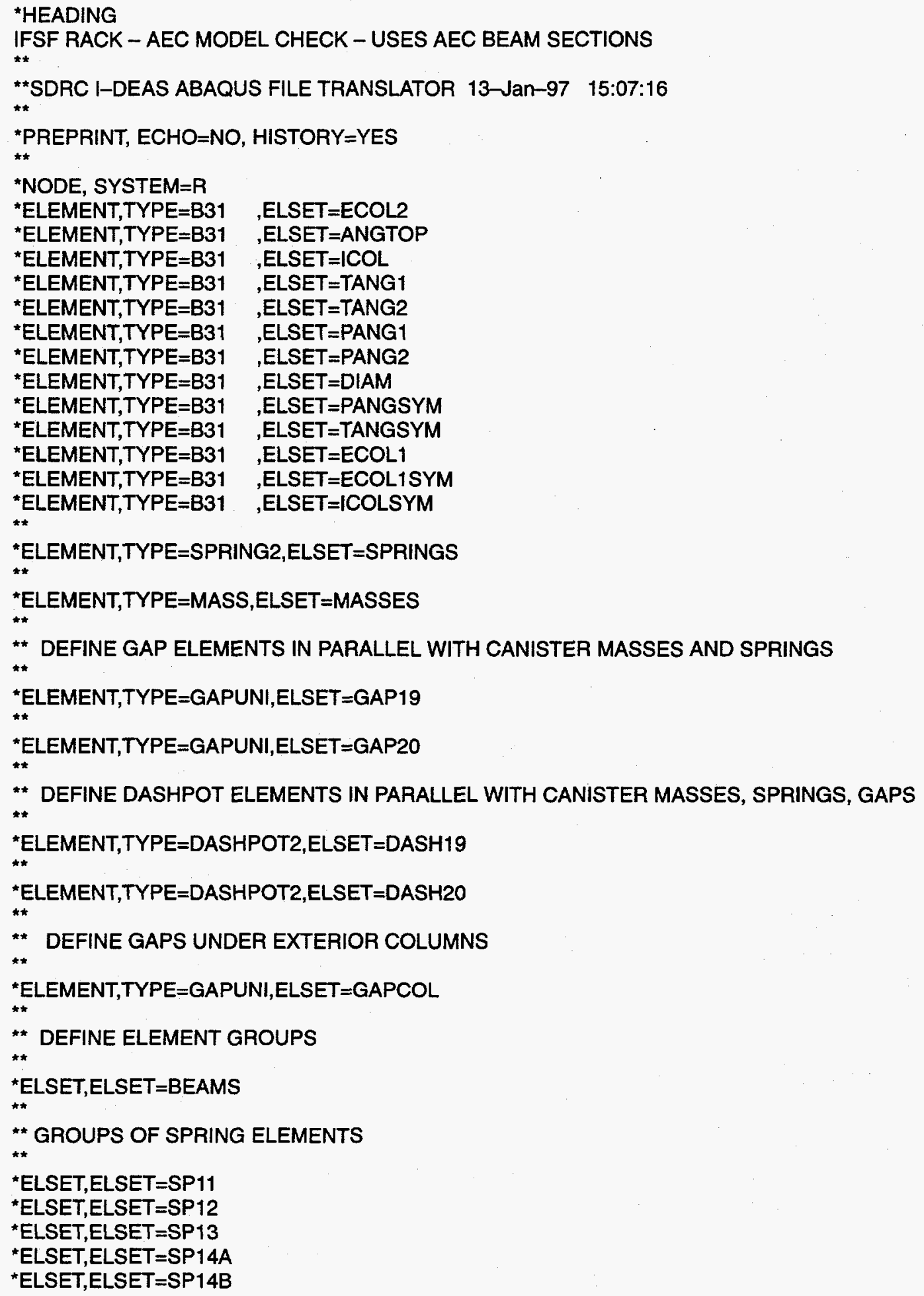


-ELSET,ELSET=SP15

-ELSET,ELSET=SP16A

${ }^{*}$ ELSET,ELSET $=S P 16 B$

*ELSET,ELSET=SP17

${ }^{\star}$ ELSET,ELSET $=S P 18$

*ELSET,ELSET=SP19

*ELSET,ELSET $=S P 20$

*ELSET,ELSET=SP24

*ELSET,ELSET=SP25

*ELSET,ELSET=SP26

${ }^{\star}$ ELSET,ELSET $=S P 27$

*ELSET,ELSET=SP28

*ELSET,ELSET=SP29

*ELSET,ELSET=SP30

${ }^{\star}$ ELSET,ELSET=SP31

$\star \star$

**

*BEAM GENERAL SECTION,ELISET=ECOL2,DENSITY = 1.04808E-06,ZERO= 7.133E+01

** USING AEC PROPERTIES HIERE:

$3.6144,3.5998,0 ., 11.1705,8.5702,0 ., 0$.

$0.0,1.0,0.0$

29000., 11154., 6.500000E-06

**

*BEAM GENERAL SECTION,ELISET=ANGTOP,DENSITY $=8.98606 E-07, Z E R O=7.133 E+01$

** USING AEC PROPERTIES HIERE:

$1.6848,0.8004,0.0,3.1996,0.0290,0 ., 0$.

$0.0,1.0,0.0$

29000., 11154., 6.500000E-06

*SHEAR CENTER

$0.0,1.1576860$

**

*BEAM GENERAL SECTION,ELSET=ICOL,DENSITY= 7.33859E-07,ZERO= 7.133E+01

** USING AEC PROPERTIES HIERE:

$6.5808,22.7992,0 ., 22.7992,38.1999,0 ., 0$.

$0.0,1.0,0.0$

29000., 11154., 6.500000E-06

**

*BEAM GENERAL SECTION,ELSET=TANG1,DENSITY $=7.33859 E-07, Z E R O=7.133 E+01$

** USING AEC PROPERTIES HERE:

4.2336, 16.4291, 0.0, 3.8859, 8.9994, 0., 0 .

$-1.0,0.0,0.0$

29000., 11154., 6.500000E-06

**

*BEAM GENERAL SECTION,ELSET=TANG2,DENSITY = 7.33859E-07,ZERO= 7.133E+01

** USING AEC PROPERTIES HERE:

4.2336, 16.4291, 0.0, 3.8859, 8.9994, 0., 0 .

$0.0,1.0,0.0$

29000., 11154., 6.500000E-06

**

*BEAM GENERAL SECTION,ELSET=PANG1,DENSITY $=8.98606 E-07, Z$ ZRO $=7.133 E+01$

** USING AEC PROPERTIES HIERE:

$1.8864,1.5801,0.0,1.0306,1.5303,0 ., 0$.

$-1.0,0.0,0.0$

29000., 11154., 6.500000E-06

$\star *$

${ }^{\star} B E A M$ GENERAL SECTION,ELSET=PANG2,DENSITY $=8.98606 E-07, Z E R O=7.133 E+01$

** USING AEC PROPERTIES HERE:

$1.8864,1.5801,0.0,1.0306,1.5303,0 ., 0$.

$0.0,1.0,0.0$

29000., 11154., 6.500000E-06 
${ }^{\star}$ BEAM GENERAL SECTION,ELSET=DIAM,DENSITY $=7.33859 E-07, Z E R O=7.133 E+01$

** USING AEC PROPERTIES HERE:

$3.0960,5.2898,0.0,5.2898,8.8211,0 ., 0$.

$0.0,1.0,0.0$

29000., 11154., 6.500000E-06

$\star *$

*BEAM GENERAL SECTION,ELSET=ECOL1,DENSITY $=1.04808 E-06, Z E R O=7.133 E+01$

** USING AEC PROPERTIES HERE:

$3.6144,11.1705,0 ., 3.5998,8.5702,0 ., 0$.

$0.0,1.0,0.0$

29000., 11154., 6.500000E-06

\#*

**

** SYMMETRY BEAMS HAVE 1/2 CROSS SECTION PROPERTIES:

**

*BEAM GENERAL SECTION,ELSET=PANGSYM,DENSITY $=8.98606 E-07, Z E R O=7.133 E+01$

** USING AEC PROPERTIES HERE:

$0.9432,0.7901,0.0,0.5153,0.7652,0 ., 0$.

$-1.0,0.0,0.0$

29000., 11154., 6.500000E-06

**

*BEAM GENERAL SECTION,ELSET $=$ TANGSYM,DENSITY $=7.33859 E-07, Z E R O=7.133 E+01$

** USING AEC PROPERTIES HERE:

$2.1168,8.2146,0.0,1.9430,4.4997,0 ., 0$.

$-1.0,0.0,0.0$

29000., 11154., 6.500000E-06

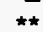

${ }^{\star}$ BEAM GENERAL SECTION,ELSET=ECOL1SYM,DENSITY $=1.04808 E-06, Z E R O=7.133 E+01$

** USING AEC PROPERTIES HERE:

$1.8072,5.5852,0 ., 1.7999,4.2851,0 ., 0$.

$0.0,1.0,0.0$

29000., 11154., 6.500000E-06

**

*BEAM GENERAL SECTION,ELSET $=\mid$ COLSYM,DENSITY $=7.33859 E-07, Z E R O=7.133 E+01$

** USING AEC PROPERTIES HERE:

$3.2904,11.3996,0 ., 11.3996,19.1000,0 ., 0$.

$0.0,1.0,0.0$

29000., 11154., 6.500000E-06

**

$\star *$

*MASS,ELSET=MASSES

0.00475

**

** DEFINE GAPS UNDER EXTERIOR COLUMNS

**

*GAP, ELSET $=$ GAPCOL

$0 ., 0 ., 0 ., 1$.

** DEFINE DASHPOTS, GAPS, AND SPRINGS BETWEEN MASSES

**

*DASHPOT, ELSET=DASH19

3,3

0.2

*DASHPOT, ELSET=DASH2O

3,3

0.2

$\star *$

${ }^{*}$ GAP, ELSET $=$ GAP19

$0.4125,0 ., 0 .,-1$. 
*GAP, ELSET=GAP20

$0 ., 0 ., 0 ., 1$.

*SPRING,ELSET=SP19

3,3

0.1

*SPRING,ELSET=SP20

3,3

0.1

**

** DEFINE OTHER AEC SPRINGS

*SPRING,NONLINEAR,ELSET=SP11

4,4

$-68.97,-.48512$

$-65.45,-.362685$

$-60.25,-.209638$

$-56.28,-.113344$

$-53.55,-.061280$

$-51.41,-.029188$

$-50.24,-.016290$

$-49.54,-.010851$

$-48.74,-.006893$

$-45.75,-.001885$

$-43.19,-.000786$

$-39.40,-.000215$

$-36.29,-.000043$

$-31.28,-1 . E-6$

$0 ., 0$,

$31.28,1 . \mathrm{E}-6$

$36.29, .000043$

$39.40, .000215$

43.19,.000786

$45.75, .001885$

$48.74, .006893$

$49.54, .010851$

$50.24, .016290$

$51.41, .029188$

$53.55, .061280$

$56.28, .113344$

$60.25, .209638$

$65.45, .362685$

$68.97, .48512$

**

*SPRING,NONLINEAR,ELSET=SP12 4,4

$-68.97,-.970240$

$-65.45,-.725370$

$-60.25,-.419276$

$-56.28,-.226688$

$-53.55,-.122561$

$-51.41,-.058377$

$-50.24,-.032580$

$-49.54,-.021702$

$-48.74,-.013787$

$-45.75,-.003769$

$-43.19,-.001572$

$-39.40,-.000430$

$-36.29,-.000087$

$-31.28,-1 . E-6$ 
$0 ., 0$,

31.28,1.E-6

$36.29, .000087$

$39.40, .000430$

$43.19, .001572$

$45.75, .003769$

$48.74, .013787$

$49.54, .021702$

$50.24, .032580$

$51.41, .058377$

$53.55, .122561$

$56.28, .226688$

$60.25, .419276$

$65.45, .725375$

$68.97, .970240$

**

*SPRING,NONLINEAR,ELSET=SP13

4,4

$-68.97,-1 . E-6$

$0 ., 0$.

68.97,1.E-6

**

*SPRING,NONLINEAR,ELSET=SP14A

4,4

$-390.50,-.259276$

$-363.60,-.206088$

$-326.80,-.110469$

$-296.10,-.039852$

$-281.90,-.016401$

$-275.50,-.008445$

$-270.10,-.003476$

$-268.00,-.002206$

$-266.90,-.001859$

$-252.90,-.000539$

$-229.70,-.000105$

$-216.90,-.000027$

$-199.20,-1 . E-6$

$0 ., 0$.

199.20,1.E-6

216.90,.000027

229.70,.000105

$252.90, .000539$

$266.90, .001859$

268.00,.002206

270.10,.003476

$275.50, .008445$

281.90,.016401

296.10,.039852

$326.80, .110469$

$363.60, .206088$

$390.50, .259276$

**

*SPRING,NONLINEAR,ELSET=SP14B

4,4

$-390.50,-.259276$

$-363.60,-.206088$

$-326.80,-.110469$

$-296.10,-.039852$

$-281.90,-.016401$

$-275.50,-.008445$

$-270.10,-.003476$ 


$$
\begin{aligned}
& -268.00,-.002206 \\
& -266.90,-.001859 \\
& -252.90,-.000539 \\
& -229.70,-.000105 \\
& -216.90,-.000027 \\
& -199.20,-1 . E-6 \\
& 0 ., 0 . \\
& 199.20,1 . E-6 \\
& 216.90, .000027 \\
& 229.70, .000105 \\
& 252.90, .000539 \\
& 266.90, .001859 \\
& 268.00, .002206 \\
& 270.10, .003476 \\
& 275.50, .008445 \\
& 281.90, .016401 \\
& 296.10, .039852 \\
& 326.80, .110469 \\
& 363.60, .206088 \\
& 390.50, .259276 \\
& \star \star
\end{aligned}
$$

*SPRING,NONLINEAR,ELSET $=$ SP15

4,4

$-390.50,-.518553$

$-363.60,-.412175$

$-326.80,-.220938$

$-296.10,-.079704$

$-281.90,-.032801$

$-275.50,-.016889$

$-270.10,-.006952$

$-268.00,-.004413$

$-266.90,-.003719$

$-252.90,-.001077$

$-229.70,-.000209$

$-216.90,-.000054$

$-199.20,-1 . E-6$

$0 ., 0$.

199.20,1.E-6

$216.90, .000054$

229.70,.000209

$252.90, .001077$

$266.90, .003719$

$268.00, .004413$

$270.10, .006952$

$275.50, .016889$

$281.90, .032801$

$296.10, .079704$

$326.80, .220938$

$363.60, .412175$

$390.50, .518553$

**

"SPRING,NONLINEAR,ELSET=SP16A

4,4

$-390.50,-1 . E-6$

$0 ., 0$.

$390.50,1 . E-6$

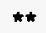

*SPRING,NONLINEAR,ELSET $=$ SP16B

4,4

$-390.50,-1 . E-6$

$0 ., 0$. 
$390.50,1 . E-6$

*

*SPRING,NONLINEAR,ELSET=SP17

3,3

$-11.388,-.00001$

$0 ., 0$.

$7.069, .00745$

$7.0691, .084$

$11.388,1.080$

**

*SPRING,NONLINEAR,ELSET=SP18

3,3

$-5.6940,-.00001$

$0 ., 0$.

$3.5345, .00745$

$3.53455, .084$

$5.6940,1.080$

เ

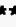

"SPRING,NONLINEAR,ELSET=SP24

3,3

$-1000000 .,-12$.

$0 ., 0$.

$1000000 ., 12$.

**

"SPRING,NONLINEAR,ELSET=SP25

4,4

$-643.9,-.551134$

$-631.2,-.503757$

$-589.3,-.367466$

$-548.4,-.251150$

$-519.0,-.176096$

$-489.2,-.108767$

$-460.4,-.054081$

$-434.0,-.016669$

$-417.6,-.002489$

$-414.3,-.001493$

$-396.1,-.000242$

$-383.9,-.000051$

$-344.1,-1 . E-6$

$0 ., 0$.

$344.1,1 . E-6$

$383.9, .000051$

$396.1, .000242$

$414.3, .001493$

$417.6, .002489$

$434.0, .016669$

$460.4,054081$

$489.2, .108767$

$519.0, .176096$

$548.4, .251150$

$589.3, .367466$

$631.2, .503757$

$643.9, .551134$

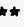

*SPRING,NONLINEAR,ELSET=SP26 4,4

$-321.95,-.551134$

$-315.60,-.503757$

$-294.65,-.367466$

$-274.20,-.251150$ 


$$
\begin{aligned}
& -259.50,-.176096 \\
& -244.60,-.108767 \\
& -230.20,-.054081 \\
& -217.00,-.016669 \\
& -208.80,-.002489 \\
& -207.15,-.001493 \\
& -198.05,-.000242 \\
& -191.95,-.000051 \\
& -172.05,-1 . \mathrm{E}-6 \\
& 0 ., 0 . \\
& 172.05,1 . \mathrm{E}-6 \\
& 191.95, .000051 \\
& 198.05, .000242 \\
& 207.15, .001493 \\
& 208.80, .002489 \\
& 217.00, .016669 \\
& 230.20, .054081 \\
& 244.60, .108767 \\
& 259.50, .176096 \\
& 274.20, .251150 \\
& 294.65, .367466 \\
& 315.60, .503757 \\
& 321.95, .551134 \\
& \star \star
\end{aligned}
$$

*SPRING,NONLINEAR,ELSET=SP27

4,4

$-191.20,-1.104436$

$-158.35,-.433579$

$-140.41,-.161853$

$-131.98,-.066452$

$-128.08,-.032779$

$-124.49,-.009527$

$-123.01,-.002784$

$-122.84,-.002387$

$-120.71,-.000728$

$-119.37,-.000409$

$-118.49,-.000285$

$-117.26,-.000179$

$-114.09,-.000058$

$-103.89,-1 . E-6$

$0 ., 0$.

103.89,1.E-6

$114.09, .000058$

$117.26, .000179$

$118.49, .000285$

$119.37, .000409$

$120.71, .000728$

$122.84, .002387$

$123.01, .002784$

$124.49, .009527$

$128.08, .032779$

$131.98, .066452$

$140.41, .161853$

$158.35, .433579$

$191.20,1.104436$

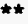

*SPRING,NONLINEAR,ELSET=SP28

4,4

$-95.600,-1.104436$

$-79.175,-.433579$

$-70.2050,-.161853$ 


$$
\begin{aligned}
& -65.9900,-.066452 \\
& -64.0400,-.032779 \\
& -62.2450,-.009527 \\
& -61.5050,-.002784 \\
& -61.4200,-.002387 \\
& -60.3550,-.000728 \\
& -59.6850,-.000409 \\
& -59.2450,-.000285 \\
& -58.6300,-.000179 \\
& -57.0450,-.000058 \\
& -51.9450,-1 . \mathrm{E}-6 \\
& 0 ., 0 . \\
& 51.9450,1 . \mathrm{E}-6 \\
& 57.0450, .000058 \\
& 58.6300, .000179 \\
& 59.2450, .000285 \\
& 59.6850, .000409 \\
& 60.3550, .000728 \\
& 61.4200, .002387 \\
& 61.5050, .002784 \\
& 62.2450 . .009527 \\
& 64.0400, .032779 \\
& 65.9900, .066452 \\
& 70.2050, .161853 \\
& 79.1750, .433579 \\
& 95.6000,1.104436 \\
& \star *
\end{aligned}
$$

*SPRING,NONLINEAR,ELSET=SP29

4,4

$-306.12,-.528898$

$-256.01,-.205588$

$-228.71,-.076556$

$-215.92,-.031990$

$-210.05,-.016528$

$-204.81,-.006271$

$-202.49,-.003147$

$-201.81,-.002676$

$-193.29,-.000767$

$-187.91,-.000402$

$-184.40,-.000258$

$-179.49,-.000125$

$-173.18,-.000038$

$-159.52,-1 . E-6$

$0 ., 0$.

159.52,1.E-6

173.18 .000038

$179.49, .000125$

$184.40, .000258$

$187.91, .000402$

193.29,.000767

$201.81, .002676$

$202.49, .003147$

$204.81, .006271$

$210.05, .026528$

$215.92, .031990$

$228.71,076556$

$256.01, .205588$

$306.12, .528898$

$\star *$

"SPRING,NONLINEAR,ELSET =SP30

4,4 
$-34.485,-.48512$

$-32.725,-.362685$

$-30.125,-.209638$

$-28.140,-.113344$

$-26.775,-.061280$

$-25.705,-.029188$

$-25.120,-.016290$

$-24.770,-.010851$

$-24.370,-.006893$

$-22.875,-.001885$

$-21.595,-.000786$

$-19.700,-.000215$

$-18.145,-.000043$

$-15.640,-1 . E-6$

0.,0.0,

15.640,1.E-6

$18.145, .000043$

$19.700, .000215$

$21.595, .000786$

$22.875, .001885$

$24.370, .006893$

$24.770, .010851$

$25.120, .016290$

$25.705, .029188$

26.775,.061280

28.140,.113344

$30.125, .209638$

$32.725, .362685$

$34.485, .48512$

**

*SPRING,NONLINEAR,ELSET=\$SP31

4,4

$-195.25,-.259276$

$-181.80,-.206088$

$-163.40,-.110469$

$-148.05,-.039852$

$-140.95,-016401$

$-137.75,-.008445$

$-135.05,-.003476$

$-134.00,-.002206$

$-133.45,-.001859$

$-126.45,-.000539$

$-114.85,-.000105$

$-108.45,-.000027$

$-99.600,-1 . E-6$

$0 ., 0$.

99.600,1.E-6

108.45,.000027

114.85,.000105

$126.45, .000539$

133.45,.001859

$134.00, .002206$

$135.05, .003476$

$137.75, .008445$

$140.95, .016401$

148.05,.039852

$163.40, .110469$

$181.80, .206088$

$195.25, .259276$

*

"* END OF SPRING DEFINITIONS 
**

** DEFINE CONSTRAINT EQUATIONS FOR MASSES IN VERTICAL DIRECTION ONLY ** "EQUATION

** NODE SETS FOR BOUNDARY CONDITIONS

${ }^{*}$ NSET,NSET $=$ SYMNDS

*NSET,NSET=BASENDS

*NSET,NSET=VFIXNDS

*NSET,NSET $=$ VFSPNDS

**

** MASS SPRING NODES TO FIX IN ALL DIRECTIONS:

**

${ }^{\star}$ NSET, NSET=MASSSPND

**

** DEFINE NODE SETS FOR STATIC SEISMIC LOADS

*NSET,NSET $=B T I E R$

**

${ }^{*}$ NSET,NSET $=$ MTIER

**

*NSET,NSET $=$ TTIER

** DEFINE ELEMENT SET FOR DEAD WEIGHT LOAD

**

${ }^{\star}$ ELSET, ELSET=ALLEL

** DEFINE NODE SET FOR CANISTER UPLIFT

**

*NSET,NSET=MASSNDS

**

** DEFINE NODE SET, TIES MASS Z DISPLACEMENT TO STRUCTURE

**

*NSET, NSET $=$ MASSST

**

** DEFINE NODE SET FOR CANISTER IMPACT

\#*

*NSET,NSET=IMPACT

**

*NSET,NSET=ROT3

*NSET,NSET=ROT4

*NSET,NSET $=$ ROT2

*NSET,NSET $=13 \mathrm{C}$

*NSET,NSET $=$ D3A

*NSET,NSET $=\mathrm{D} 3 B$

"NSET,NSET=12B

*NSET,NSET $=$ D2A

*NSET,NSET $=$ D4A

*NSET,NSET $=14 \mathrm{D}$

*NSET,NSET $=$ D4B

*NSET,NSET $=$ D4C

${ }^{*} \mathrm{MPC}$

**

*EQUATION

**

*BOUNDARY

SYMNDS, XSYMM

BASENDS, 1,2

VFIXNDS, 3

VFSPNDS, 3

MASSSPND, ENCASTRE

MASSNDS, 1,2 
MASSST, 1,2

**

*ELSET, ELSET=GAPS

GAP19, GAP20, GAPCOL

"ELSET, ELSET =COLS

ECOL1, ECOL2, ICOL

**

**

** STEP 1 - APPLY DEAD WEIGHT LOAD (1G DOWN)

*STEP,NLGEOM, AMPLITUDE=RAMP, INC=1000

${ }^{*}$ STATIC

$0.05,1 ., 0.01, .35$

${ }^{\star}$ RESTART,WRITE,FREQUENCY $=1$

*MONITOR, NODE=3855, DOF=2

${ }^{*} \mathrm{CLOAD}, \mathrm{OP}=\mathrm{NEW}$

*DLOAD, OP=NEW

ALLEL, GRAV, 386.4, 0., 0., -1 .

*PRINT,CONTACT $=$ YES,FREQUENCY $=1$

*NODE PRINT,FREQUENCY=10,00,NSET=MASSST

$\mathrm{U}$

*NODE PRINT,FREQUENCY $=1000, N S E T=M A S S N D S$

$\mathrm{U}$

*EL PRINT,FREQUENCY=1000, ELSET=GAP19

S11

E11

${ }^{*}$ EL PRINT,FREQUENCY $=1000$, ELSET $=$ GAP20

S11

E11

*EL PRINT,FREQUENCY=1000, ELSET=GAPCOL

S11

E11

*NODE FILE,FREQUENCY $=1$

RF

U

*EL FILE,FREQUENCY=1, ELSET=BEAMS

SF

${ }^{*}$ EL FILE,FREQUENCY=1, ELSET=GAPS

S

E

${ }^{\star}$ END STEP

**

**

** STEP 2 - APPLY BASIC SEISMIC LOADS ON CANISTERS \& RACK

**

*STEP,NLGEOM, AMPLITUDE=RAMP, INC=2000

*STATIC

$0.025,1 ., 0.0005,0.1$

*RESTART,WRITE,FREQUENCY $=5$

${ }^{*} \mathrm{CLOAD}, \mathrm{OP}=\mathrm{MOD}$

BTIER,2,0.021774

BTIER,3,-0.004761

MTIER,2,0.028326

MTIER,3,-0.004761

TTIER,2,0.018010

TTIER,3,-0.002724

MASSNDS, $3,-0.293760$

*END STEP

**

**

* STEP 3 - APPLY CANISTER IMPACT LOADS 
**

*STEP,NLGEOM, AMPLITUDE=RAMP, INC=2000

*STATIC

$0.01,1,0.00001,0.025$

**CLOAD, OP=MOD, AMPLITUDE=CANHITS

**IMPACT,2,1.

**

${ }^{*} \mathrm{CLOAD}, \mathrm{OP}=\mathrm{MOD}$

IMPACT, 2,0.46

*END STEP 


\section{INPUT DATA, PLASTIC BEAM MODEL}

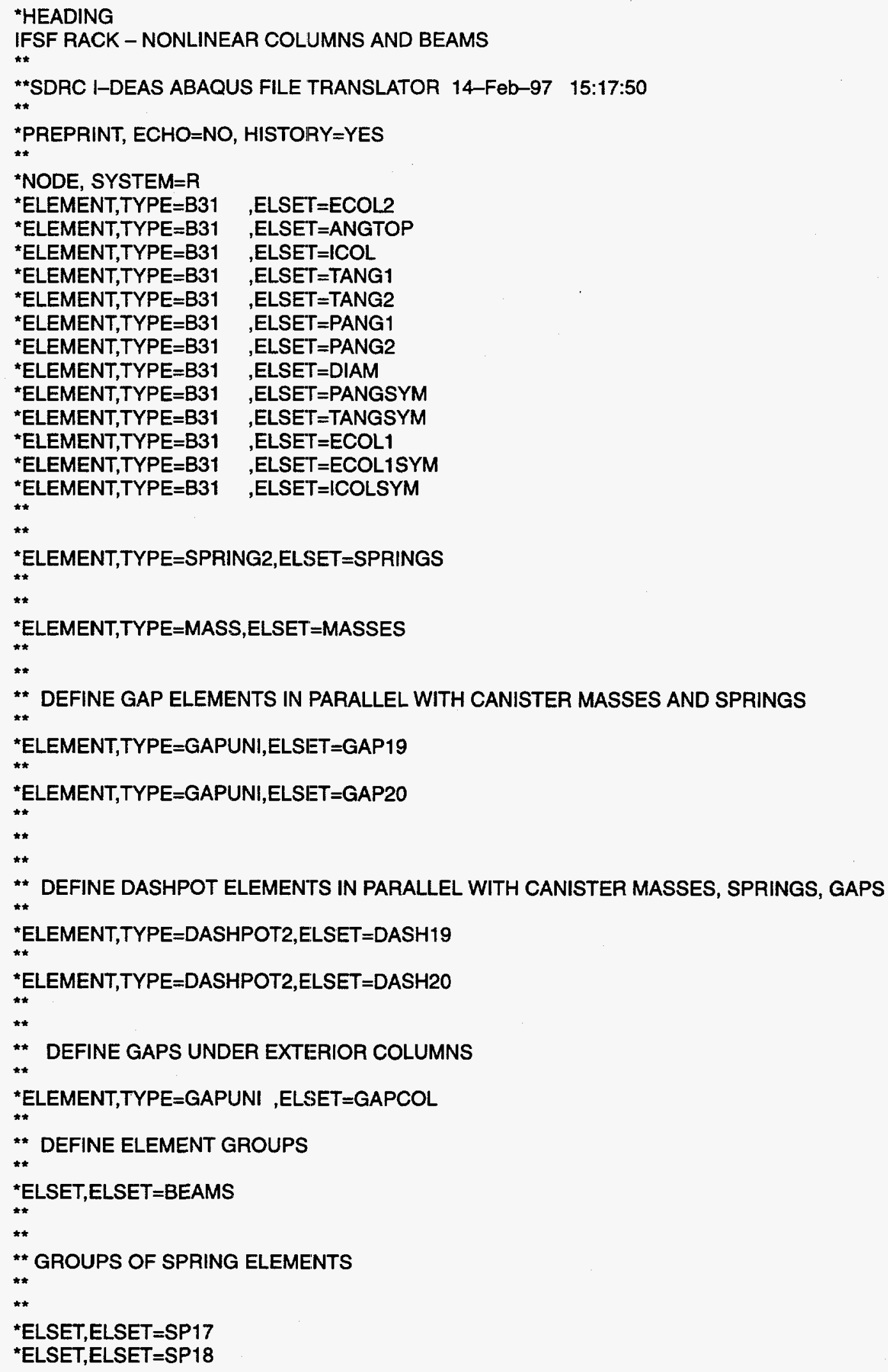




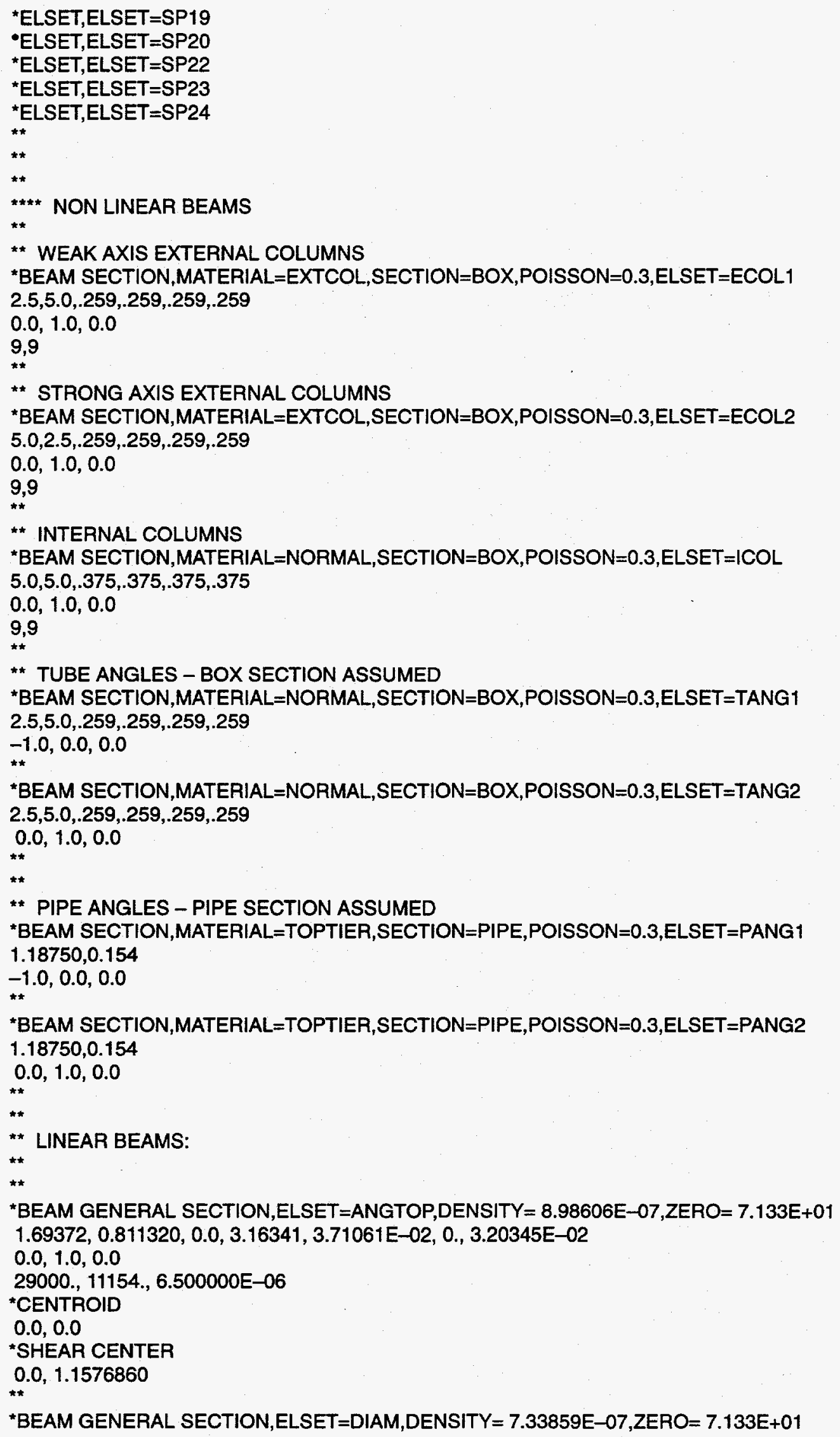


$3.08747,5.28290,0.0,5.28289,8.92521,0 ., 0.0$

$0.0,1.0,0.0$

29000., 11154., 6.500000E-06

"CENTROID

$0.0,0.0$

"SHEAR CENTER

$0.0,0.0$

**

** SYMMETRY BEAMS HAVE 1/2 CROSS SECTION PROPERTIES AND ARE LINEAR:

**

*BEAM GENERAL SECTION,ELSET=PANGSYM,DENSITY= 8.98606E-07,ZERO=7.133E+01

** 1.90986, 1.53912, 0.0, 1.03381, 2.11303, $0 ., 0.0$

$0.95493,0.76956,0.0,0.516905,1.056515,0 ., 0.0$

$-1.0,0.0,0.0$

29000., 11154., 6.500000E-06

*CENTROID

$0.0,0.0$

"SHEAR CENTER

$0.0,7.818882 E-02$

*BEAM GENERAL SECTION,ELSET=TANGSYM,DENSITY = 7.33859E-07,ZERO= $7.133 E+01$

** 4.24284, 1.60605E+01, 0.0, 3.86455, 1.06304E+01, 0., 3.01876

$2.12142,8.03025,0.0,1.932275,5.3152,0 ., 1.50938$

$-1.0,0.0,0.0$

29000., 11154., 6.500000E-06

*CENTROID

$0.0,0.0$

"SHEAR CENTER

$5.628222 E-04,3.450500 E-02$

"BEAM GENERAL SECTION,ELSET=ECOL1SYM,DENSITY $=1.04808 E-06, Z E R O=7.133 E+01$

$\star * 3.44381,1.01258 E+01,0.0,3.35069,8.699080,0 ., 1.13765$

$1.721905,5.0629,0.0,1.675345,4.34954,0 ., 0.568825$

$0.0,1.0,0.0$

29000., 11154., 6.500000E-06

"CENTROID

$0.0,0.0$

*SHEAR CENTER

$0.0,0.0$

**

*BEAM GENERAL SECTION,ELSET =|COLSYM,DENSITY $=7.33859 E-07, Z E R O=7.133 E+01$

** 6.57536, 2.12036E+01, 0.0, 2.12036E+01, 4.49502E+01, 0., 0.0

$3.28768,10.60180,0.0,10.60180,22.4751,0 ., 0.0$

$0.0,1.0,0.0$

29000., 11154., 6.500000E-06

"CENTROID

$0.0,0.0$

"SHEAR CENTER

$0.0,0.0$

**

**

*MASS,ELSET=MASSES

0.00475

**

*MATERIAL,NAME=NORMAL

"ELASTIC

29000.,0.3

^DENSITY

7.33859E-7 
*PLASTIC

27.0,0.

$36.044,0.002$

$40.295,0.01666$

$50.707,0.0278$

$55.193,0.0373$

$62.024,0.0748$

$64.960,0.111$

$80.000,0.693$

*MATERIAL,NAME=TOPTIER

*ELASTIC

29000.,0.3

'DENSITY

8.98606E-7

*PLASTIC

27.0,0.

$36.044,0.002$

$40.295,0.01666$

$50.707,0.0278$

$55.193,0.0373$

$62.024,0.0748$

$64.960,0.111$

$80.000,0.693$

*MATERIAL,NAME=EXTCOL

^ELASTIC

29000.,0.3

${ }^{*}$ DENSITY

1.04808E-6

*PLASTIC

27.0,0.

$36.044,0.002$

$40.295,0.01666$

$50.707,0.0278$

$55.193,0.0373$

$62.024,0.0748$

$64.960,0.111$

$80.000,0.693$

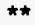

** DEFINE GAPS UNDER EXTERIOR COLUMNS

**

*GAP, ELSET = GAPCOL

$0 ., 0 ., 0 ., 1$.

**

** DEFINE DASHPOTS, GAPS, AND SPRINGS BETWEEN MASSES

$\star \star *$

-DASHPOT, ELSET=DASH19

3,3

0.5

${ }^{\star}$ DASHPOT, ELSET=DASH20

3,3

0.5

**

*GAP, ELSET =GAP19

$0.4125,0 ., 0 .,-1$.

**

*GAP, ELSET =GAP20

0., 0., 0., 1.

**

*SPRING,ELSET=SP19

3,3

0.1 
**

** DEFINE OTHER AXIAL ONLY AEC SPRINGS

**

**

*SPRING,NONLINEAR,ELSET=SP17

3,3

$-11.388,-.00001$

$0 ., 0$.

$7.069, .00745$

$7.0691, .084$

$11.388,1.080$

*SPRING,NONLINEAR,ELSET=SP18

3,3

$-5.6940,-.00001$

$0 ., 0$.

$3.5345, .00745$

$3.53455, .084$

$5.6940,1.080$

$\star \star$

*SPRING, NONLINEAR,ELSET=SP24

3,3

$-1000000 .,-12$.

$0 ., 0$.

$1000000 ., 12$.

**

** END OF SPRING DEFINITIONS

**

** DEFINE CONSTRAINT EQUATIONS FOR MASSES IN VERTICAL DIRECTION ONLY

**

*EQUATION

**

**

** NODE SETS FOR BOUNDARY CONDITIONS

**

*NSET,NSET=SYMNDS

$\star \star$

*NSET,NSET=BASENDS

*NSET,NSET=VFIXNDS

"NSET,NSET=VFSPNDS

**

** MASS SPRING NODES TO FIX IN ALL DIRECTIONS:

**

*NSET, NSET=MASSSPND

**

* DEFINE NODE SETS FOR STATIC SEISMIC LOADS

*NSET,NSET $=B$ TIER

**

*NSET,NSET=MTIER

**

*NSET,NSET $=$ TTIER

**

* DEFINE ELEMENT SET FOR DEAD WEIGHT LOAD

**

*ELSET, ELSET=ALLEL

**

* DEFINE NODE SET FOR CANISTER UPLIFT 


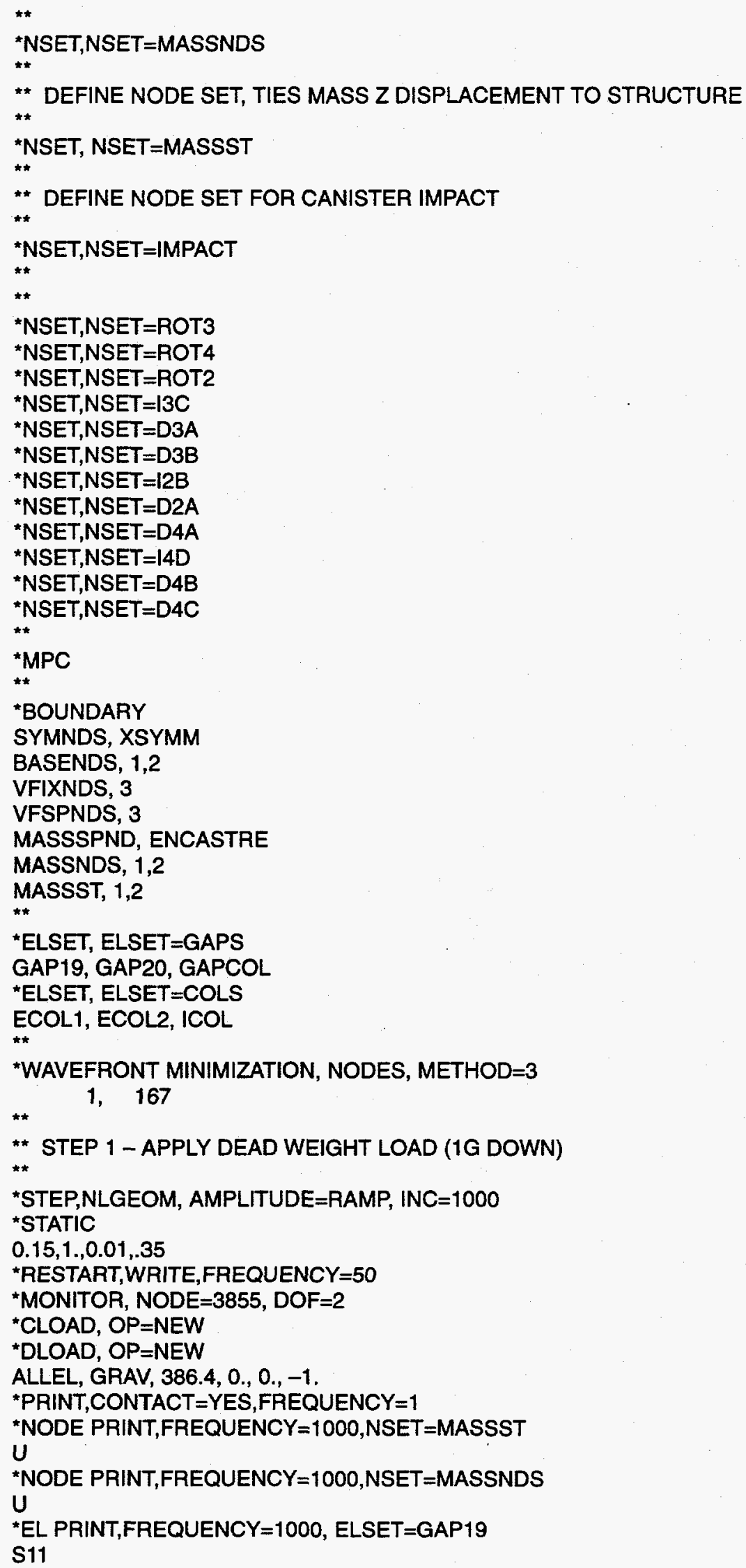




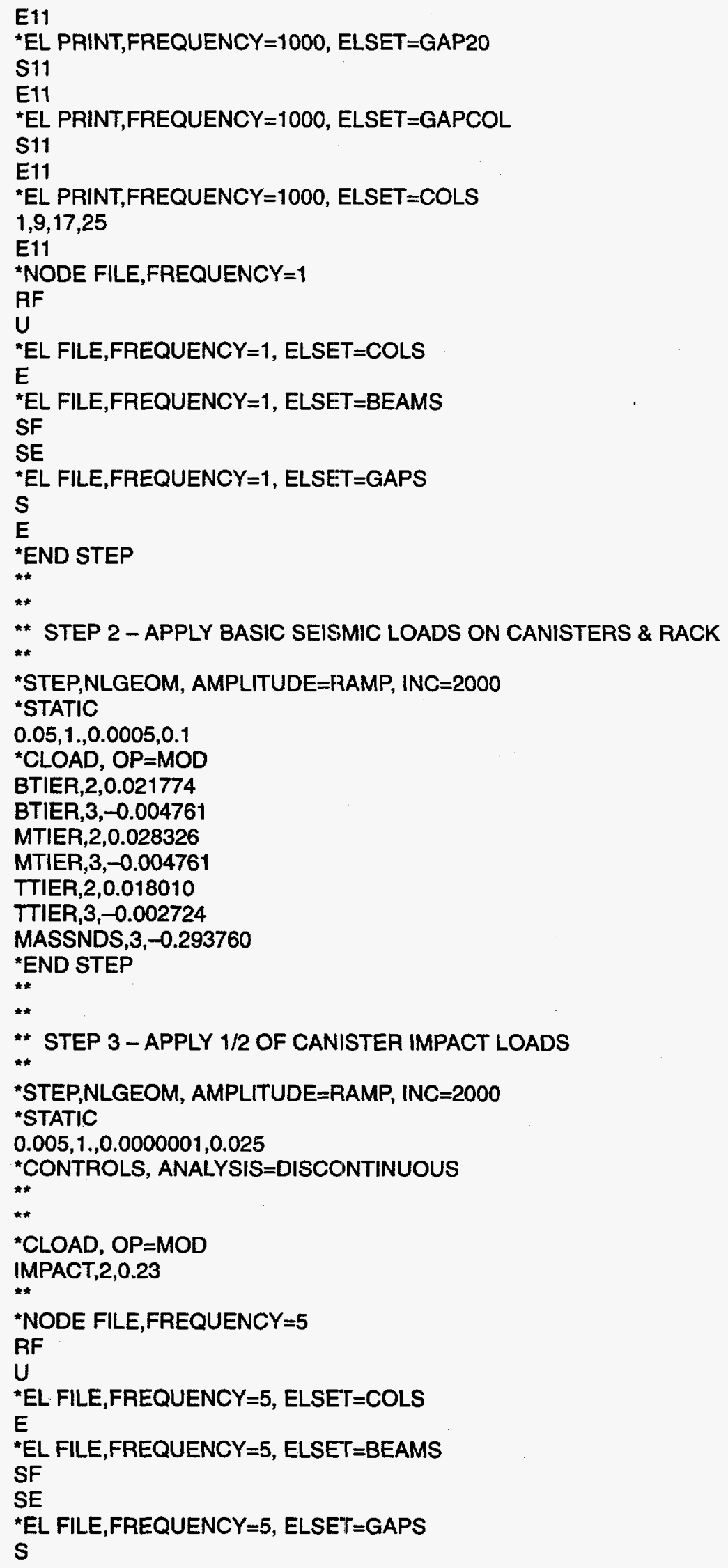


E

*END STEP

**

** STEP 4 - APPLY REST OF CANISTER IMPACT LOADS

*STEP,NLGEOM, AMPLITUDE=RAMP, INC=2000

*STATIC

$0.005,1 ., 0.0000001,0.025$

*CONTROLS, ANALYSIS=DISCONTINUOUS

**

**

*CLOAD, OP=MOD

IMPACT, 2,0.46

*END STEP

$\star \star$ 